\title{
Efficacy and Safety of Platelet Inhibitors
}

\author{
Ornella Binazon $^{1,2}$, Audrey Dubois-Gaché ${ }^{1,3}$, Radu M. Nanau ${ }^{1,4}$, Manuela G. Neuman ${ }^{1,4}$ \\ ${ }^{1}$ In Vitro Drug Safety and Biotechnology, Toronto, ON, Canada; ${ }^{2}$ Faculty of Pharmacy, University Paris Descartes, \\ Paris, France; ${ }^{3}$ Faculty of Pharmacy, University Paul Sabatier, Toulouse, France; ${ }^{4}$ Department of Pharmacology and \\ Toxicology, Faculty of Medicine, University of Toronto, Toronto, ON, Canada.
}

Received, November 5, 2012; Revised, January 1, 2013; Accepted, January 5, 2013; Published, January 7, 2012.

\begin{abstract}
Ischemic heart disease is the second leading cause of death in the world. The proportion of deaths resulting from this condition has decreased in the last two decades, mainly as a result of improved primary and secondary prevention of cardiovascular events, as well as the development of patient awareness and medical and pharmacological management. The purpose of the present review is to analyze pathophysiological events leading to platelet involvement in cardiovascular thrombosis, as well as the role of pharmacogenetics in modulating the risk of cardiovascular disorders. The present work was performed using a PubMed search with combinations of key words relevant to the subject in both English and French. In addition to the pharmacokinetic and pharmacodynamic characteristics of platelet inhibitors, this work reviews the efficacy and adverse events observed during the clinical trials with these drugs. This review further summarizes possible therapeutic drug monitoring strategies for antiplatelet drugs. The novelty of this work is the description of the lymphocyte toxicity assay as a specific method of diagnosing and predicting possible idiosyncratic adverse events attributable to antiplatelet medication.
\end{abstract}

This article is open to POST-PUBLICATION REVIEW. Registered readers (see "For Readers") may comment by clicking on ABSTRACT on the issue's contents page.

\section{INTRODUCTION}

In 2006, the Public Health Agency of Canada published a report indicating that cardiovascular (CV) diseases were the leading cause of death in Canada. The number of deaths from CV diseases represented $30 \%$ of all reported deaths. Of these, $23 \%$ (16109 individuals) were due to myocardial infarction (MI). In 2009, this number increased to $21000(1)$.

MI, with or without ST segment elevation, is part of acute coronary syndrome (ACS). ACS describes a clinical heart condition characterized by the formation of blood clots, resulting from the erosion and rupture of an atheromatous coronary plaque (2). ACS represents a burden for the society and to the healthcare system. In Canada, it is estimated that almost $2 \%$ of the general population will be hospitalized with MI, with treatment costs expected to surpass $\$ 1.6$ billion (3). The same trend is observed in the US, where ACS costs exceed $\$ 150$ billion annually. Moreover, almost $20 \%$ of MI patients are rehospitalized within 1 year (4). In France, ischemic heart diseases caused 38806 deaths in 2006, which represented $27 \%$ of all $\mathrm{CV}$ deaths. Ischemic heart disease is recognized as the second leading cause of death for men and women. However, the incidence of mortality as result of this condition has decreased between 1990 and 2006 due to improvement of primary and secondary prevention of $\mathrm{CV}$ events and the development of patient management (5).

The pathophysiological process of $\mathrm{CV}$ diseases is linked to plaque formation, fibrogenesis and inflammation. Inflammation is the first step involved in the formation of an atheromatous plaque. Inflammation activates the endothelium and permits the recruitment of monocytes and lymphocytes, which are further responsible for the production of proinflammatory cytokines (6). Matrix proteases degrade the fibrous layer of the endothelium. Ultimately, inflammation induces apoptosis of plaque cells, leading to the formation of a lipid core inside the plaque. Erosion is brought about by a combination of weakening of the fibrous layer of the endothelium and stimuli applied onto the plaque (7). When an atherosclerotic plaque ruptures, blood cells come into contact with thrombogenic elements from the lipid center, inducing activation of platelets, blood clotting and the formation of thrombi $(7,8)$.

\footnotetext{
Corresponding Author: Manuela G. Neuman Ph.D.; Department of Pharmacology and Toxicology, In Vitro Drug Safety and Biotechnology MaRS Discovery District, 101 College Street, South Tower, Suite 300, Lab 351; Toronto, Ontario, Canada; E-Mail: manuela.neuman@utoronto.ca
} 


\section{Abbreviations}

ACS, acute coronary syndrome

ADP, adenosine diphosphate

$\mathrm{CABG}$, coronary-artery bypass surgery

COX-1, cyclooxygenase-1

$\mathrm{CV}$, cardiovascular

CYP, cytochrome p450

HIV, human immunodeficiency virus

HPLC, high-performance liquid chromatography

GP, glycoprotein

$\operatorname{IgE}$, immunoglobulin E

HSR, hypersensitivity syndrome reactions

LC, liquid chromatography

LSC, liquid scintillation counting

MI, myocardial infarction

MS, mass spectrometry

NSTEMI, non-ST segment elevation myocardial

infarction

PCI, percutaneous coronary intervention

STEMI, ST segment elevation myocardial

infarction

TDM, therapeutic drug monitoring

$\mathrm{TXA}_{2}$, thromboxane A2

UA, unstable angina

VASP, vasodilator-stimulated phosphoprotein

The accumulation and migration of thrombi can lead to partial or total obstruction of coronary arteries, resulting in a lack of oxygen to the heart. This leads to a spectrum of heart conditions ranging from chest pain (unstable angina (UA)) to MI and heart damage (7).

Platelets play a critical role in the pathophysiology of $\mathrm{CV}$ diseases through their interaction with the injured endothelium (9). They are involved in the build-up of atherosclerotic plaque, while their activation is partially stimulated by systemic inflammatory reaction syndrome (10). Platelets are also associated with an inflammatory process that leads to the secretion of pro-inflammatory agents such as chemokines, eicosanoids, thromboxane A2 $\left(\mathrm{TXA}_{2}\right)$, leukotrienes and platelet activation factor (11). Inflammation leads to coagulation through an extrinsic pathway involving thrombin generation. This process is initiated by tissue factor, a transmembrane protein released by damaged endothelial tissue or synthesized by macrophages. A higher abundance of tissue factor is associated with mononuclear cells present in the atherosclerotic plaque, probably due to the pro-inflammatory environment to which these cells are exposed, particularly interleukin (IL)-6 (8). In blood, tissue factor combines with factor VIIa, forming a complex that is able to catalyze the conversion of factor $\mathrm{X}$ to factor $\mathrm{Xa}$. Factor
$\mathrm{Xa}$, together with factor $\mathrm{Va}$, factor II (prothrombin) and $\mathrm{Ca}^{2+}$, further forms a prothrombinase complex that leads to the generation of thrombin (factor IIa). Thrombin in turn strengthens coagulation by converting fibrinogen into fibrin (factor Ia), thereby allowing fibrin polymerization $(8,12)$. Fibrin stimulates the activity of neutrophils, platelets and endothelial cells. Platelets are essential for the pathogenesis of inflammation-mediated thrombosis, as is the case with ACS (8). Platelet adhesion and activation can be further achieved through contact with subendothelial collagen present on the tunica intima, the innermost layer of a blood vessel that can become exposed upon the rupture of an atherosclerotic plaque. Other molecules can also activate platelets, including platelet-activating factor, a pro-inflammatory mediator, as well as thrombin itself (8).

Hemostasis is a normal physiological function whose deregulation can lead to obstruction of blood vessels with thrombi, giving rise to MI or UA (13). This process is composed of 3 phases, namely initiation, activation/aggregation and stabilization. Hemostasis is initiated by exposed collagen from the subendothelial matrix leading to adherence of platelets by binding to the $\alpha_{2} \beta_{1}$ (glycoprotein (GP) Ia/IIa) and $\alpha_{\mathrm{IIb}} \beta_{3}$ (GP IIb/IIIa) membrane integrins, and GP receptors present on platelet membrane. Vasoconstriction further improves adherence $(13,14)$. Platelet rolling, the initial contact between platelets and the exposed endothelium, is mediated by selectins present on the surfaces of both platelets and endothelial cells. For example, P-selectin is rapidly translocated to the plasma membrane following inflammatory stimuli. Platelet accumulation on the surface of the activated endothelium is mediated by the $\alpha_{\mathrm{IIb}} \beta_{3}$ integrin (15). Platelet adhesion is further mediated by the $\alpha_{V} \beta_{3}$ integrin (vitronectin receptor) and the GP $\mathrm{Ib} / \mathrm{IX} / \mathrm{V}$ (von Willebrand factor) receptor. The vitronectin receptor can be activated by IL-1 $\beta$ or thrombin, while the von Willebrand factor is produced by the injured tissue (13-15). The von Willebrand factor fixes GP Ib-IX, a platelet membrane receptor, and this binding induces a conformational change that captures and activates platelets, leading to thrombus formation $(14,16)$. The GP VI receptor associates with the $\mathrm{Fc}$ receptor $\gamma$ subunit and activates phospholipase $\mathrm{C}_{\gamma 2}$. Phospholipase $\mathrm{C}$ phosphorylation and activation can be further mediated by integrins. Phospholipase $\mathrm{C}$ activation can hydrolyze phosphatidylinositol-4,5bisphosphate membrane protein into the secondary messengers inositol-3-phosphate and diacylglycerol. Inositol-3-phosphate leads to 
mobilization of intracellular $\mathrm{Ca}^{2+}$, which provokes platelets contractions through cytoskeletal reorganization and filopodia extension. $\mathrm{Ca}^{2+}$ and adenosine diphosphate (ADP) are essential to initiate platelet coagulation (16).

Fibrinogen binds the GP IIb/IIIa platelet membrane receptor, creating a bridge between two platelets. Thrombin transforms fibrinogen into fibrin, which is an insoluble protein that activates platelets and strengthens coagulation through the formation of a platelet-fibrin thrombus (8). Moreover, thrombin triggers an amplification of platelet aggregation by activating tissue factor $\mathrm{V}$, which in turn activates tissue factor XIII, stabilizing the clots through the formation of an insoluble fiber. During normal physiological conditions, building of clots is balanced by their destruction following reconstruction of the endothelial layer, a process known as fibrinolysis (12).

Because thrombotic events are involved in the pathogenesis of atherosclerosis and artery diseases, most therapies for ACS modulate platelet function and coagulation. Platelet inhibitors in combination with aspirin are recommended for the prevention of $\mathrm{CV}$ events.

\section{METHODS}

The present work was performed following a PubMed search with combinations of key words using one of "antiplatelet drug", "platelet inhibitor", "clopidogrel", "ticlopidine", "prasugrel" and "ticagrelor", and one of "efficacy", "adverse drug reaction", "hypersensitivity reaction", "metabolism", "pharmacokinetics", "pharmacodynamics", "pharmacogenomics", "therapeutic drug monitoring" and "clinical trials". A considerable portion of the safety and efficacy data was compiled from the various clinical trials involving clopidogrel, while the main conclusions presented are those of the respective study investigators. Additional material used to support the main findings was retrieved from the Google Scholar database. Furthermore, reports from various health agencies in Canada and France were consulted, as well as the product monographs of the drugs studied. Reviewed material includes work published in both English and French.

\section{RESULTS AND DISCUSSION}

\section{I) Review of Platelet Inhibitors a. Pharmacology}

Platelet inhibitors are molecules aimed at reducing atherothrombotic events. These agents are often used in combination with aspirin in order to induce sufficient vasodilation to avoid the formation of blood clots. Cyclooxygenase (COX)1 normally produces $\mathrm{TXA}_{2}$, a platelet aggregation agent. Aspirin is an irreversible COX-1 inhibitor that leads to inhibition of $\mathrm{TXA}_{2}$ formation, such that platelets are permanently inhibited until new platelets are synthetized. A $75 \mathrm{mg}$ dose is sufficient to obtain adequate inactivation of COX1. Aspirin also reduces the incidence of both MI and $\mathrm{CV}$ death when administered during the acute phase of ACS (7). Platelet inhibitors currently in use include the thienopyridine family (ticlopidine, clopidogrel and prasugrel) and the newer cyclopentyl triazolopyrimidine, ticagrelor. The oldest of the thienopyridines, ticlopidine (Ticlid $($ )), was commercialized in 1991 by Sanofi. The second and the most widely-used thienopyridine is clopidogrel (Plavix $\left.{ }^{\circledR}\right)$, marketed by Sanofi and Bristol Myers Squibb in 1997. The latest thienopyridine is prasugrel (Effient $\left.{ }^{\circledR}\right)$, put on the market in 2009 by Eli Lilly and Company. In 2011, Astra Zeneca developed a new antiplatelet agent, the cyclopentyl triazolopyrimidine ticagrelor (Brilinta $\AA)(17,18)$. Thienopyridines have similar structures and similar mechanisms of action. As prodrugs, these molecules require hepatic biotransformation by cytochrome p450 (CYP) 2C19, 3A4, 3A5, 2C9, 2B6 or esterases in order to induce antiplatelet effects (17). The active metabolite (with a thiol moiety) binds irreversibly to the G-coupled receptor $\mathrm{P}_{2} \mathrm{Y}_{12}$, forming a disulfide bond with one of the receptor's cysteine residues. $\mathrm{P}_{2} \mathrm{Y}_{12}$ is a purinergic receptor belonging to the seven transmembrane class of receptors, found on platelet cell membranes. A second purinergic receptor, $\mathrm{P} 2 \mathrm{Y}_{1}$, initiates the platelet response to ADP, while $\mathrm{P} 2 \mathrm{Y}_{12}$ promotes this response. $\mathrm{P} 2 \mathrm{Y}_{12}$ thus plays an important role in the activation of platelets and their aggregation. The interaction between ADP and $\mathrm{P}_{2} \mathrm{Y}_{12}$ results in adenylate cyclase inhibition, leading to platelet aggregation (19). Initially, the interaction between ADP and P2 $\mathrm{Y}_{12}$ causes a change in the platelet's shape from a disc to a sphere with pseudopodia. This change involves $\mathrm{Ca}^{2+}$ influx, intracellular $\mathrm{Ca}^{2+}$ mobilization and actin polymerization. Platelet aggregation is further mediated by the change in conformation of GP IIb/IIIa complexes on the platelet's surface, which become fibrinogen receptors upon activation. Fibrinogen links platelets by creating a bridge between two GP IIb/IIIa platelet receptors (19). ADP comes from the general circulation after the transformation of ATP as result of cellular or tissue damage. ADP can be further produced by CD39, an integral 
membrane protein on the endothelial cells. Collagen and thrombin also cause platelet shape changes and promote platelets to secrete the contents of their granules, including ADP and thus amplifying the mechanism. The binding of collagen and thrombin to their receptors further leads to the production of the pro-aggregation agent $\mathrm{TXA}_{2}$ (19). Blockage of the $\mathrm{P}_{2} \mathrm{Y}_{12}$ receptor leads to inactivation of platelets, with blockage of GP IIb/IIIa, which in turn inhibits the rest of the aggregation stunt to ultimately prevent clot formation (20). In contrast to thienopyridines, the structure of ticagrelor is very similar to adenosine. As such, it does not bind the ADP site, but rather it reversibly binds another site on the $\mathrm{P}_{2} \mathrm{Y}_{12}$ receptor. Ticagrelor is therefore a non-competitive inhibitor. The conformational change of this receptor is blocked and activation and aggregation of platelets cannot occur (21). Ticagrelor is already an active drug, but in vitro evidence suggests that it can also be further converted to an active metabolite by CYP3A4/5 (22-24).

\section{b. Indications and Dosages}

Long-term platelet inhibitors administered orally are indicated for the prevention of atherothrombotic events in patients suffering from MI, ischemic stroke, established peripheral arterial disease and ACS (patients undergoing stent placement following percutaneous coronary intervention (PCI), ST segment elevation MI (STEMI) or non-ST segment elevation MI (NSTEMI)). Platelet inhibitors were indeed shown to reduce the occurrence of new $\mathrm{CV}$ events after certain surgeries (25). These drugs are useful to limit the prothrombogenic effect of reperfusion treatment (thrombolysis and primary angioplasty) in ACS with ST segment elevation. In ACS without ST segment elevation, they prevent vascular occlusion and therefore MI (7). The Canadian Cardiology Society and Health Canada recommends aspirin (75-162mg daily) in combination with clopidogrel ( $75 \mathrm{mg}$ daily) as the gold standard treatment in patients who underwent a CV event (26). The synergy between aspirin and platelet inhibitors provides a greater antiplatelet effect, and subsequently a more significant reduction in the risk of atherothrombotic disease.

Aspirin is recommended for acute MI and acute ischemic stroke, as well as for prophylaxis in MI and CV disease. Clopidogrel is the standard treatment used for the prevention of atherothrombotic events. This drug is indicated in adults who have recently experienced MI (treatment to be initiated between 7-35 days post event), ischemic stroke (treatment to be initiated between 7 days-6 months post event) or peripheral arterial disease (27).

Other thienopyridines or ticagrelor are used as second-line in long-term treatment following ACS in cases of adverse drug reactions (ADR) or low responsiveness to clopidogrel. Ticlopidine is recommended to reduce the risk of thrombotic stroke (fatal or nonfatal) in patients who have experienced stroke precursors, and in patients who have had a complete thrombotic stroke (28). The newer generation thienopyridine prasugrel, co-administered with aspirin, is indicated for the prevention of atherothrombotic events in patients with ACS (UA/NSTEMI or STEMI) undergoing primary or delayed PCI (29). Ticagrelor, coadministered with aspirin, is also indicated for the prevention of atherothrombotic events in adults with ACS (UA/NSTEMI or STEMI), including patients managed medically, or with PCI or coronary-artery bypass surgery (CABG) (30). Dosing indications for platelet inhibitors prescribed as dual-therapy in combination with aspirin are presented in Table $1(21,31)$.

In 2011, the Canadian Cardiovascular Society published guidelines about the use of antiplatelet therapy in the outpatient setting (26). Indefinite therapy with low dose aspirin (75-162 $\mathrm{mg}$ /day) is recommended in all patients with acute or chronic ischemic heart disease. Indefinite therapy with clopidogrel $(75 \mathrm{mg} /$ day $)$ is recommended in all patients with acute or chronic ischemic heart disease who are intolerant or allergic to aspirin. Clopidogrel plus aspirin treatment is recommended in STEMI patients (up to 1 year in patients with no excessive risk of major bleeding, otherwise up to 14 days) and in non-ST segment elevation ACS patients (up to 1 year in patients with no excessive risk of major bleeding, otherwise up to 1 month). Continuing daily therapy beyond 1 year is recommended in all ACS patients who are managed medically with a low risk of bleeding (26). Furthermore, in the absence of contraindications to aspirin therapy, clopidogrel plus aspirin treatment is also recommended post-PCI in patients with bare metal stent implantation (up to 1 year in patients with no excessive risk of major bleeding, otherwise up to 1 month), as well as drug-eluting stent implantation (1 year). Patients with recent bleeding or at increased risk of bleeding may benefit from a short course of clopidogrel plus aspirin ( $\geq 2$ weeks) post-PCI, while patients with an increased risk of stent thrombosis and a tolerable risk of bleeding are encouraged to continue dual-therapy beyond 1 year (26). 
While not recommended in patient with an increased risk of bleeding, patients likely to undergo CABG within 7 days, patients with a

\begin{tabular}{lcccc}
\hline \multicolumn{5}{l}{ Table 1. Dosing indications for platelet inhibitors } \\
\hline \multicolumn{7}{c}{ Dosing Frequency } & Maintenance Dose & Loading Dose & Aspirin Dose/day \\
Ticlopidine & Twice daily & $250 \mathrm{mg}$ & $500 \mathrm{mg}$ & $75-162 \mathrm{mg}$ \\
Clopidogrel & Daily & $75 \mathrm{mg}$ & $300 \mathrm{mg}$ & $75-162 \mathrm{mg}$ \\
Prasugrel & Daily & $10 \mathrm{mg}$ & $60 \mathrm{mg}$ & $75-162 \mathrm{mg}$ \\
Ticagrelor & Twice daily & $90 \mathrm{mg}$ & $180 \mathrm{mg}$ & $\leq 100 \mathrm{mg}$ \\
\hline
\end{tabular}

history of stroke or transient ischemic attack, and patients $>75$ years or age and $<60 \mathrm{~kg}$ in weight, prasugrel plus aspirin may prove beneficial in ACS patients with stent implantation who are at increased risk of stent thrombosis (1 year) (26).

\section{c. Pharmacokinetics and Metabolism}

All thienopyridines are prodrugs and require hepatic biotransformation. They each have their own metabolism pathway. Hepatic metabolism of ticlopidine by CYP2C19 and 2B6 results in the production of four metabolites, of which only UR-4501, the oxidation product of 2-oxoticlopidine, is active. The parent molecule is $98 \%$ bound to plasma proteins (32).

The first step in clopidogrel hepatic metabolism involves the formation of an intermediate metabolite, 2-oxo-clopidogrel, via CYP2C19, 3A4, 2B6 and 1A2. Subsequently, this compound is transformed to an active thiol metabolite which forms a disulfide bridge by irreversibly binding to a cysteine residue on the platelet ADP receptor, causing inhibition of platelet aggregation (17, 24, 27, 33-35). Only $15 \%$ of the prodrug is metabolized to the active metabolite, while bioactivation by human carboxylesterase 1 leads directly to an inactive carboxylic acid metabolite $(85 \%$ of circulating metabolites) (36). Clopidogrel metabolites were shown in vitro to have the 2-\{1-[1-(2chlorophenyl)-2-methoxy-2-oxoethyl]-4-sulfanyl3-piperidinylidene acetic acid primary structure, with the active metabolite showing $S$ configuration at carbon 7 and $\mathrm{Z}$ configuration at the carbon 3-16 double bond (34). Due to its extensive metabolism via hepatic enzymes, clopidogrel presents complex pharmacokinetic and pharmacodynamic properties.

The third generation thienopyridine prasugrel requires only one step to be biotransformed to its active metabolite, known as R-138727, via a thiolactone intermediate compound which is rapidly formed in the intestine through the action of human carboxylesterase 2 . More than $50 \%$ of the administered dose is absorbed and around $90 \%$ of the parent drug is transformed into the active metabolite (24). CYP3A4/5 and 2B6 are the main CYPs involved in the metabolism of prasugrel, with a minor contribution from CYP2C19 and 2C9 (24). Interestingly, intestinal metabolism plays an important role in the formation of the active metabolite, with a major proportion of active metabolite being formed by CYP3A4 via first-pass intestinal metabolism (17). Prasugrel has a faster antiplatelet effect than ticlopidine and clopidogrel. Genetic variability has a less pronounced effect on its pharmacodynamics. Prasugrel also provides better protection against MI or stent thrombosis, yet it carries a more pronounced risk of hemorrhagic events. Genetic polymorphisms have a lesser impact on these parameters as well, making this third generation thienopyridine an important alternative to clopidogrel (31).

While ticagrelor is already an active drug, CYP3A4 and 3A5 were shown in vitro to lead to the creation of an active metabolite that is nearly 3 times as potent as the parent compound $(21,24)$. Since ticagrelor is a substrate of CYP3A4 and Pglycoprotein, drug-drug interactions can occur. For instance, if ticagrelor is co-administered with the CYP3A4 inhibitor ketoconazole, exposure to ticagrelor would be increased 7-fold, while maximum plasma concentration $\left(\mathrm{C}_{\max }\right)$ and area under the curve (AUC) for its active metabolite were reduced by $89 \%$ and $56 \%$ respectively (35). Ticagrelor has rapid onset and offset of action. Indeed, the antiplatelet effect is observed as soon as $30 \mathrm{~min}$ post-administration $(200 \mathrm{mg})$ and full clearance of ticagrelor and its active metabolite, with functional recovery of platelet aggregation returning to normal, was observed $48 \mathrm{~h}$ postadministration $(20,22,24)$. Table 2 displays the pharmacokinetic profiles of ticlopidine and ticagrelor, as well as those of the active metabolites of clopidogrel, prasugrel and ticagrelor $(22,37-41)$.

\section{II) Clinical Trials with Platelet Inhibitors}

Clinical trials assessing the efficacy and safety of platelet inhibitors are introduced in Table 3 (4284). 


\begin{tabular}{llllll}
\hline \multicolumn{2}{l}{ Table 2. Pharmacokinetic profiles of active metabolites of platelet inhibitors } & & \\
\hline Parameters & Ticlopidine & Clopidogrel active & Prasugrel active metabolite & Ticagrelor & Ticagrelor active \\
& $(250 \mathrm{mg})$ & metabolite $(300 \mathrm{mg})$ & $(60 \mathrm{mg} \mathrm{LD} / 10 \mathrm{mg}$ MD) & $(200 \mathrm{mg})$ & metabolite $(200 \mathrm{mg})$ \\
\hline Cmax $(\mathrm{ng} / \mathrm{mL})$ & 573 & 35.9 & $453 / 56$ & 923 & 264 \\
Tmax $(\mathrm{h})$ & 1.9 & 1.0 & 0.5 & 1.5 & 3.0 \\
AUC $(\mathrm{ng} / \mathrm{h} / \mathrm{mL})$ & $\mathrm{AUC}_{(0-\infty)} 1808$ & $\mathrm{AUC}_{(0-\infty)} 43.8$ & $\mathrm{AUC}_{(0-\mathrm{t})} 460 / 54$ & $\mathrm{AUC}_{(0-\mathrm{t})} 6591$ & $\mathrm{AUC}_{(0-\mathrm{t})} 2477$ \\
$\mathrm{~T} 1 / 2(\mathrm{~h})$ & 6.9 & 0.52 & 7.4 & 8.4 & 3.0 \\
\hline
\end{tabular}

\section{a. Characteristics of Patients Requiring Antiplatelet Therapy}

The Euro Heart Survey describes characteristics of patients requiring antiplatelet therapy (85). Electrocardiogram results showed ST segment elevation in almost $47.0 \%$ of 6385 ACS patients included in this study. The mean age in this population was 64.7 . The most common diagnosis was typical angina (80.8\%). Some common characteristics of this population include a history of past/current smoking, diabetes mellitus, hypertension and hyperlipidemia. A considerable amount of ACS patients were found to have had previous $\mathrm{MI}, \mathrm{PCI}, \mathrm{CABG}$, stroke, transient ischemic attack or renal failure (85). Similar values were observed in the CURE study (43). In this study, female gender was $38.5 \%$, with a mean age for the sample of 64.2. Common comedication included aspirin, warfarin, heparin, GP IIb/IIIa inhibitors, proton pump inhibitors (PPI), $\mathrm{Ca}^{2+}$ channel blockers (CCB), $\beta$-blockers, statins, angiotensin-converting enzyme inhibitors, lipid-lowering agents and intravenous nitrate (43, 85). The ACTIVE study describes a slightly older population (mean age 70.2), with an even wider array of co-medication (86).

\section{III) Efficacy of Platelet Inhibitors}

The main findings of the clinical trials assessing the efficacy of platelet inhibitors are described in detail in Table 4.

Efficacy of platelet inhibitors is typically assessed in terms of the primary study end-points defined in each clinical trial. These often include $\mathrm{CV}$ death, recurrent MI, recurrent ischemia or stroke, as well as the occurrence of stent thrombosis. CAPRIE was the earliest trial to test the antiplatelet drug clopidogrel, proving its superiority over aspirin. Subsequent trials further showed the efficacy of dual-therapy with clopidogrel and aspirin to be superior to either clopidogrel or aspirin alone. The combination of platelet inhibitors and aspirin was thus accepted as the standard of care. Yusuf et al. report a reduction of $20 \%$ in the incidence of MI, death and stroke with clopidogrel $(75 \mathrm{mg} /$ day) plus aspirin over aspirin alone (43). This combination prevented about 50 major vascular events per
1000 patients treated (51). Dual-therapy with platelet inhibitors and aspirin was shown to be superior to aspirin and placebo for the long-term prevention of ischemic complications after a coronary angioplasty, while the risk of bleeding is also increased $(7,43,46)$. Clopidogrel and aspirin, dual-therapy decreases mortality and morbidity rates $(46,54)$. The use of lower doses of aspirin (e.g. $75 \mathrm{mg} /$ day) is generally recognized as being comparable to that of higher doses, with the added benefit of a reduced hemorrhagic risk (87).

\section{a. Comparative Antiplatelet Effects}

The CURE (43) and COMMIT (51) studies in particular showed the superiority of clopidogrel and aspirin dual-therapy over aspirin monotherapy in terms of a reduced risk of the combination of the primary study end points of $\mathrm{CV}$ death, MI and stroke, as well as a decreased risk of each of these end points separately. These data are presented in Table 4.

Clopidogrel was subsequently shown to be superior to ticlopidine, while both prasugrel and ticagrelor were superior to clopidogrel (Table 4). Ticagrelor inhibits platelet aggregation in a dosedependent manner (70, 71). All of ticagrelor, prasugrel and clopidogrel $600 \mathrm{mg}$ were superior to clopidogrel $300 \mathrm{mg}$ with respect to reducing the rates of major $\mathrm{CV}$ events (88). Ticagrelor was associated with superior antiplatelet effects during both the first hours of treatement as well as during maintenance therapy (78). Furthermore, nonresponsiveness to clopidogrel can be overcome by ticagrelor (74). Effects of ticagrelor were similar between clopidogrel responders and clopidogrel non-responders (74). Clinical superiority of prasugrel over clopidogrel was more pronounced in patients with diabetes mellitus (66), while the superiority of ticagrelor over clopidogrel was more pronounced in patients with chronic kidney disease compared to patients with normal renal function (77).

\section{b. Inhibition of Platelet Aggregation}

One method used to compare the efficacy of antiplatelet agents is the inhibition of platelet aggregation (IPA). IPA is calculated as the 
percentage of decrease in the maximal platelet aggregation (MPA) from baseline according to the formula [1-(MPA $\left.\left.\mathrm{t} / \mathrm{MPA}_{0}\right)\right] \times 100 \%$ (89).

Using patients with coronary arterial diseases, Nawarskas and Snowden calculated a maximum IPA with $20 \mu \mathrm{mol} / \mathrm{L}$ ADP (agonist) after loading dose (LD) of $30-50 \%$ for clopidogrel, $75-80 \%$ for prasugrel and $80-90 \%$ for ticagrelor $(21)$. The time to maximum IPA was $4-8 \mathrm{~h}$ for clopidogrel, $2-4 \mathrm{~h}$ for prasugrel and $2-4 \mathrm{~h}$ for ticagrelor (21). In healthy volunteers (18-65 years of age) who weren't taking aspirin, the maximum IPA with 20 $\mu \mathrm{mol} / \mathrm{L}$ ADP after LD was $35 \pm 24.5 \%$ for clopidogrel and $78.8 \pm 9.2 \%$ for prasugrel. The time to maximum IPA was $4 \mathrm{~h}$ for clopidogrel and $1 \mathrm{~h}$ for prasugrel (89). Prasugrel was found to have a superior IPA profile to clopidogrel at therapeutic doses, with lower inter-patient variability in terms of platelet inhibition, as well as fewer patients considered poor responders or hyporesponders (63). Prasugrel generally achieved a faster and higher IPA than clopidogrel $(17,89,90)$. Similarly, IPA was greater and maximum IPA was achieved faster in ticagrelor patients compared to clopidogrel patients (72). Ticagrelor further induced IPA in patients with poor response to clopidogrel, as well as inducing further IPA in patients who responded to clopidogrel (71). Ticagrelor was associate with a lower prevalence of high on-treatment platelet reactivity compared to clopidogrel $(p<0.0001)$ in the combined data from the ONSET/OFFSET and RESPOND clinical trials, which can help explain the lower incidence of $\mathrm{CV}$ adverse events observed in ticagrelor patients compared to clopidogrel patients (91).

\section{c. Interindividual Response Variability}

The effectiveness of antiplatelet drugs to reduce ischemic events after ACS is modulated by interindividual response variability to the antiplatelet agents themselves, non-compliance, progression of atherosclerosis and a modest IPA response. As a relatively high incidence of nonresponsiveness and ADRs is encountered, proper optimization of treatment is becoming a priority for physicians. Drug discontinuation can be responsible for a recurrence of $\mathrm{CV}$ events and adverse outcomes. This is applicable for all platelet inhibitors but particularly for ticagrelor due to its rapid onset and offset of antiplatelet action. The IPA for ticagrelor is lower than that seen for clopidogrel $48 \mathrm{~h}$ after taking the drug. For instance, the IPA with ticagrelor after $72 \mathrm{~h}$ is only $20 \%$, similar to the IPA for clopidogrel 5-7 days post-dose $(21,72,92)$.
Generally, lack of adherence can lead to resistance to platelet inhibitors, decreasing their activity and increasing the risk of ADRs. Two ways to define clopidogrel resistance on platelet function testing have been proposed (93). The first of these recognizes a poor response to clopidogrel treatment and is assessed by a change in ADP-induced platelet reactivity compared to baseline, while the second is high on-treatment platelet reactivity (93). Gurbel et al. define drug resistance as an absolute difference between baseline aggregation and post-treatment aggregation of $\leq 10 \%$ with $5 \mu \mathrm{mol} / \mathrm{L} \quad$ ADP (agonist) (94). Around $30 \%$ of patients treated with clopidogrel do not achieve sufficient platelet inhibition (95). High on-treatment platelet reactivity describes suboptimal IPA achieved after administration of clopidogrel LD. It is associated with the occurrence of thrombotic events following PCI, and can often be attributed to interindividual variability (96). Clopidogrel resistance is mediated by a combination of pharmacokinetic, pharmacodynamic and pharmacogenetic factors. Different elements can influence patient response to clopidogrel, including environmental, medical or genetic factors, all of which depend on adherence to therapy, age, body mass index and presence of diabetes mellitus, as well as drug and dietary inhibition of hepatic metabolism (97). For instance, diabetic and obese individuals are more likely to be poor clopidogrel responders and to develop sensitivity to ADP (93).

\section{d. Pharmacogenetics}

Patient variability first comes into play during intestinal absorption, which may be modified by the P-glycoprotein ABCB1. A C3435T single nucleotide polymorphism in the gene encoding for this efflux transporter may significantly reduce clopidogrel absorption, at either 300 or $600 \mathrm{mg}$ LD. Not surprisingly, homozygous carriers of this polymorphism were found to suffer from increased rates of CV adverse events (98). A greater focus is placed upon the genes responsible for the metabolism of platelet inhibitors, as loss-of-function (LOF) mutations in these genes are important determinants of drug reactive metabolite availability, drug resistance and the incidence of CV adverse events (93). Around $30 \%$ of clopidogrel patients have poor responsiveness to this treatment $(94,95)$. Clopidogrel poor responsiveness is due to its complex pharmacokinetic and pharmacodynamic profile, with a considerable implication of CYP2C19 (95). 
CYP2C19 is the main drug-metabolizing enzyme responsible for the formation of ticlopidine and clopidogrel active metabolites. CYP2C19 polymorphisms lead to decreased functional activity and affect the pharmacokinetic profiles, as well as the pharmacodynamic responses to these thienopyridines (99). CYP2C19*2 and $* 3$ alleles are associated with reduced prodrug metabolism, resulting in decreased levels of the active metabolite and a consequent lack of $\mathrm{P} 2 \mathrm{Y}_{12}$ inhibition. Conversely, CYP2C19*17 is associated with increased metabolism (100). Genetic variations were found to lead to a lack of response to treatment in a recent study (101). A poor metabolizer genotype is defined by two LOF alleles. This genotype occurs in $2-14 \%$ of the population, and it is highly dependent on ethnicity $(102,103)$. Intermediate metabolizers have only one LOF allele. This genotype is more common in the population (30$60 \%$ ), and its incidence also varies based on one's ethnic background $(102,103)$. The frequency of the *2 LOF allele is higher in Asians $(30 \%)$, African Americans (18\%) and Caucasians (13\%). The less common *3 LOF allele is also more wide-spread in Asians (10\%). The incidence of the *17 gain-of-function (GOF) allele is higher in Caucasians and Ethiopians (18\%), and low in Asians (4\%) (104). Consequently, the distribution of poor metabolizers (i.e. $* 2 / * 2$ or $* 3 / * 3$ homozygotes, as well as $* 2 / * 3$ compound heterozygotes) is more predominant in Asian populations (10-25\%), and to some extent in Caucasians (3\%) and Africans (4\%) (104). Gurbel et al. observed that $31 \%$ of clopidogrel patients experienced insufficient platelet inhibition after five days of treatment and 15\% after 30 days (94). A recent meta-analysis revealed that both LOF, as well as GOF mutations, have the potential to influence the pharmacological response to clopidogrel. Heterogeneity across studies makes it hard to draw a definitive conclusion (105), although inter-individual variability is a clinical issue that needs to be addressed (106).

CYP2C9 also decreases the activity of clopidogrel with respect to platelet inhibition. Both CYP2C19 and CYP2C9 play a role in clopidogrel resistance $(104,107,108)$. Diminished clopidogrel effect (109) and higher rates of CV adverse events (98) were observed in individuals with two CYP2C19 LOF alleles. On the other hand, GOF mutations are associated with a decreased incidence of $\mathrm{CV}$ adverse events but an increased risk of bleeding (105). Based on limited consensus with respect to the influence of one's CYP2C19 genetic status, genotyping is not currently recommended prior to commencing antiplatelet treatment (110). Although switching to another platelet inhibitor is one solution to bypass pharmacogenetic barriers, the same observation is valid for all antiplatelet agents whose metabolism is mainly dependent on CYP2C19 activity. Nonetheless, it was demonstrated that prasugrel metabolism is affected by gene variability to a lesser degree, owing to its one step metabolism and the relatively minor implication of CYP2C19 (99, 101).

Although to a lesser extent, thienopyridines are substrates of CYP3A4 and CYP3A5, and can thus be involved in drug-drug interactions with inhibitors (e.g. ketoconazole) or inducers (e.g. rifampicine) of these enzymes (24). The nonexpressor CYP3A5*3 allele was associated with increased rates of atherothrombotic events, as well as a higher risk of drug-drug interactions with other CYP3A4 substrates as more of the drug is shunt through this pathway (111). An increase in the clopidogrel LD (900 mg) at the beginning of the treatment can improve its efficacy, yet this was valid only in heterozygous carriers of the LOF allele $(103,112,113)$.

The liver esterase paraoxonase-1 is also implicated, with the Q192R polymorphism associated with more efficient clopidogrel bioactivation and increased clinical activity. Alternatively, a QQ192 homozygous genotype is associated with a high level of stent thrombosis, as this enzyme is a key factor associated with antiplatelet activity following clopidogrel administration (114).

CYP polymorphisms are less of an issue with regards to ticagrelor metabolism as the parent drug is already active and CYP2C19 is not involved in its biotransformation.

\section{IV) Adverse Drug Reactions}

Any substances able to produce a therapeutic effect can also provoke unwanted ADRs. The World Health Organization defines an ADR as " $a$ response to a drug that is noxious and unintended and occurs at doses normally used in man for the prophylaxis, diagnosis or therapy of disease, or for modification of physiological function". It is alternatively defined as "an appreciably harmful or unpleasant reaction, resulting from an intervention related to the use of a medicinal product, which predicts hazard from future administration and warrants prevention or specific treatment, or alteration of the dosage regimen, or withdrawal of the product" (115). There are two main types of ADRs. Type A ADRs give rise to predictable reactions. They are dose-, time- and frequency-dependent and host-independent. On 
the other hand, type B ADRs are unpredictable reactions independent of the dose, time and frequency of treatment. Type B ADRs are hostdependent $(115,116)$.

Clopidogrel is associated with ADRs due to its complex pharmacogenetic and pharmacokinetic profiles. The vast majority of ADRs associated with antiplatelet drugs are wellcharacterized in the clinical trials that assessed the efficacy and toxicity of these agents. The incidence of ADRs varies with respect to the medication regimen being investigated, as well as the characteristics of the population being assessed. The main findings of the clinical trials assessing the safety of platelet inhibitors are described in detail in Table 5. The main ADR associated with platelet inhibitors is bleeding, while close to $1 \%$ of patients exposed to clopidogrel develop severe allergic, hematologic and hepatologic ADRs (117). Other severe ADRs identified in relations to clopidogrel include diarrhea, upper gastrointestinal (GI) discomfort, intracranial hemorrhage and GI hemorrhage (42, 118). GI tract bleeding (incidence 2-3\%) is a particularly problematic ADR associated with platelet inhibitors (119-121).

While a relatively wide array of ADRs was identified in the CAPRIE trial, the first study to assess the antiplatelet effect and the safety of clopidogrel in patients with atherosclerotic vascular disease, the incidence of severe ADRs was rare and comparable between patients randomized to receive either clopidogrel or aspirin (42). Risk factors for clopidogrelassociated toxicity include documented coronary disease, documented cerebrovascular disease, or documented symptomatic peripheral arterial disease (53). As the safety and efficacy of this new thienopyridine derivative was shown, future studies have focused on the safety and efficacy of clopidogrel in combination with aspirin, compared to placebo and aspirin. Clopidogrel was associated with an increased risk of bleeding in the CURE trial (43-45). With the exception of the CURE trial, similar rates of bleeding between clopidogrel and placebo were observed in most studies comparing these two regimens. Furthermore, a higher risk of bleeding was observed for the combination of clopidogrel and aspirin, compared to placebo and aspirin (54). A recent study shows that the risk of bleeding observed with clopidogrel is dose-dependent (56, 57), while a smaller study failed to confirm this association (55). Nonetheless, clopidogrel and aspirin remains the standard treatment in ACS patients.
Ticlopidine is associated with a risk of lifethreatening blood dyscrasias, including thrombocytopenic purpura, neutropenia/agranulocytosis and aplastic anemia $(28,122)$. Other ticlopidine ADRs include GI intolerance, skin rash and severe hematologic side effects. Neutropenia and thrombocytopenic purpura was also observed. Thus, monitoring blood counts is recommended every two weeks for the first three months after initiating ticlopidine treatment (117). Previously, based on the findings of Müller et al. (58) as well as those from CLASSICS (59) and TOPPS (60), clopidogrel was shown to have a more favorable safety profile than ticlopidine, with an equal or better therapeutic potential (60). Ticlopidine is thus not used as first-line treatment due to its relatively poor safety profile. However, ticlopidine can be an important second-line drug in patients who discontinue clopidogrel treatment due to poor responsiveness, poor metabolism or hypersensitivity syndrome reactions (HSR). In this case, this is a commonly used approach to reduce risk of thrombosis after a stent implantation (123). Ticlopidine should also be reserved for patients who are intolerant or allergic to aspirin or those who have failed aspirin therapy, and as adjunctive therapy with aspirin to reduce the incidence of subacute stent thrombosis in patients undergoing successful coronary stent implantation (28).

The safety of clopidogrel was further compared to that of the third generation thienopyridine derivative, prasugrel. While bleeding events were found to be relatively infrequent (65), findings of the TRITON-TIMI 38 clinical trial point to an increased risk of bleeding in prasugrel patients, compared to clopidogrel patients $(63,64,66)$. It is interesting to note that these differences were found in the larger populations only, while being absent in subpopulations undergoing PCI $(61,68)$. Serious bleeding was associated with female sex, use of GP IIb/IIIa inhibitors, duration of intervention, age $>75$ years old, body weight $<60 \mathrm{~kg}$, and admission diagnosis of STEMI, femoral access for angiography, creatinine clearance, hypercholesterolemia and arterial hypertension $(124,125)$. However, the principal finding of the TRITON-TIMI 38 clinical trial was that prasugrel is preferred to clopidogrel due its superior benefit in reducing ischemic events $(63,126)$ and reduced mortality $(p=0.025)$ (69). Prasugrel is contraindicated in patients with a history of stroke or ischemic attacks $(97,127)$.

The PLATO study was an international, randomized, double-blind clinical trial comparing 
the safety and efficacy of clopidogrel and ticagrelor in a large cohort of ST segment elevation ACS patients with scheduled primary PCI, as well as non-ST segment elevation ACS patients (128). Bleeding was observed in ticagrelor patients, yet most reports show similar rates between ticagrelor and clopidogrel. Furthermore, there were similar rates of major bleeding, fatal bleeding or non-coronary bypassrelated major bleedings in patients with chronic kidney disease and patients with normal renal function in the PLATO cohort (77). Dyspnea, defined as shortness of breath either during exercise or at rest, is recognized as the major nonhematological ADR of ticagrelor (21). The incidence of dyspnea was found to be higher in ticagrelor patients, compared to either clopidogrel or placebo $(20,72,73,75)$. There is a doseresponse relationship between ticagrelor treatment and dyspnea $(21,70,73)$. In the PLATO trial, the incidence of dyspnea was almost 2-fold higher in ticagrelor patients compared to clopidogrel patients (75). Dyspnea often occurs during the first week of ticagrelor treatment, with most cases lasting less than $24 \mathrm{~h}$, and some lasting up to a week $(70,73,75)$. Most cases of dyspnea recorded in the ONSET/OFFSET and the PLATO trials were characterized as mild or moderate (21). Dyspnea was not associated with changes in cardiac or pulmonary function in the ONSET/OFFSET trial (73). Another ADR associated with ticagrelor was asymptomatic ventricular pauses $(70,83)$.

Clopidogrel may also induce hematotoxicity, characterized by anemia, thrombocytopenia, neutropenia and/or agranulocytosis. Recently, bone marrow toxicity was described in an in vitro model of human umbilical cord blood. Both parent drug and metabolites were toxic towards myeloid progenitor cell (129).

An interesting alternative to dual-treatment is triple therapy with aspirin, clopidogrel and cilostazol. This phosphodiesterase III inhibitor antiplatelet drug has been shown to be effective, particularly in patients suffering from diabetes mellitus, who have been shown to be generally poorer responders to clopidogrel than patients not suffering from this co-morbidity. Cilostazol was shown to be safe, as it carries no increased risk of bleeding, thus providing a treatment alternative for patients at risk of bleeding or those who cannot receive alternative antiplatelet agents (130).

\section{V) Hypersensitivity Syndrome Reactions} HSRs are examples of type B ADRs. Cases of HSR associated with antiplatelet medication are rarely reported in clinical trials. However, several case reports describe clopidogrel cutaneous HSR. A "true" HSR is defined by the triad of fever, rash and internal organ involvement (131). Around 6\% of clopidogrel patients develop HSR (132). Cutaneous reactions are the most common type of allergic reactions associated with clopidogrel exposure (42), while rash is the most common manifestation of cutaneous HSR associated with antiplatelet agents, occurring in approximately $4 \%$ of ticlopidine patients and $5 \%$ of clopidogrel patients $(117,123,133)$. Allergic ADRs are commonly referred to as HSRs, but HSRs concern both allergic and autoimmune mechanisms. Based on the definition proposed by Gell and Coombs in 1963, HSRs are undesirable reactions of the normal immune system, and include allergies and autoimmunity. These damaging, uncomfortable, or occasionally fatal reactions require a presensitized (immune) state of the host (134). Clopidogrel HSR case reports often concern people requiring chronic daily use of clopidogrel. Allergic dug HSRs are classified as type I allergic reactions (135).

The exact incidence of clopidogrel HSR is not known, but it has been observed in $1-6 \%$ of the population (132). The incidence of clopidogrel HSR was $1.6 \%$ in a large sample of 3877 PCI patients. This was even higher in older patients ( $\geq 60$ years), but that may be so because the elderly are the target population for this drug (118). The initial phase of the reaction was identified after a mean period of 5 days, with 3 main cutaneous presentations. Of the 62 probable/definite clopidogrel HSR cases observed, $49(79.0 \%)$ were characterized as generalized, pruritic, exanthematous rash, affecting predominantly the trunk, with or without involvement of the upper and lower extremities, a further $10(16.1 \%)$ patients developed rash localized in a focal or symmetrical manner, while the remaining 3 (4.8\%) cases involved symptoms and signs of angioedema, with swelling of the tongue and lips, or generalized urticaria (118). Time to onset varied with clinical severity, such that the more severe cases of generalized, pruritic, exanthematous rash were observed after a longer mean period of time. Time to onset and severity of reaction were not dependent on the clopidogrel LD used (118). A relatively low incidence of cutaneous clopidogrel HSR $(0.7 \%$ of 2701 patients undergoing PCI) was noted in another study. The onset of skin HSR was observed after a mean period of 4.5 days following clopidogrel initiation (136).

Clinical and histological data, as well as results of skin testing, suggest that clopidogrel 
HSRs can be of two types, the first of which is a delayed, lymphocyte-mediated immune reaction with cutaneous symptoms, while the other is an immediate HSR with angioedema and urticaria (118). The mechanism of clopidogrel HSR was describe by Nakamizo et al., who report a case of generalized exanthematous pustulosis and fever developed secondary to clopidogrel exposure (137). Laboratory investigation revealed leukocytosis $\left(12.9 \times 10^{9} / \mathrm{L}\right)$, with elevated eosinophils $\left(0.13 \times 10^{9} / \mathrm{L}\right)$ and neutrophils $\left(10.9 \times 10^{9} / \mathrm{L}\right)$, as well as C-reactive protein $(66$ $\mathrm{mg} / \mathrm{L})$ levels. Histologically, neutrophil infiltration, edema and spongiosis were observed, as well as eosinophils in the deeper layers. Based on these findings, $\mathrm{T}$ cell involvement is suspected, with $\mathrm{CD} 4{ }^{+} \mathrm{T}$ helper response (Th) 17, IL-17, IL-8 and neutrophils observed. A drug lymphocyte stimulation test was positive for clopidogrel, with increased IL-17A and IL-17F levels showing a Th17 response. IL-17 induces IL-8 production, which in turn attracts neutrophils (137). Use of $\beta$ blockers has been identified as a risk factor for developing clopidogrel cutaneous HSR (138).

\section{a. Cutaneous Hypersensitivity Syndrome Reactions}

Several cases of cutaneous clopidogrel HSR have been reported in the literature, the most common feature of which was rash, including maculopapular pruritic rash (133, 139), erythematous papular rash (140), generalized pruritus (141-145), diffuse rash (146) and urticarial rash (147-150). Symptoms occurred 1 day-3 weeks after initiating treatment with clopidogrel $(140,143,146,149,151,152)$. Other symptoms can include fever, hives, severe itching, swelling, angioedema, neutropenia, thrombocytopenia, lymphopenia, aseptic leukocyturia, tachycardia, rigors, abdominal pain, nausea, vomiting, as well as elevated aminotransferase, amylase and $\gamma$ glutamyltranspeptidase levels (141, 142, 144, 145, $147,148,150,151)$. Worsening of cutaneous symptoms is observed after rechallenge with the same drug (151).

Although prasugrel represents a good alternative to clopidogrel, allergic reactions have been recently observed. Cutaneous features include generalized pruritic maculopapular eruption (153), pruritic maculopapular exanthematous rash (154) and extensive pruritic maculopapular rash (155). Symptoms occurred between 2 days-1 week of initiating prasugrel treatment (153-155).

\section{b. Cross-reactivity}

Antiplatelet treatment is required in patients with ACS in order to prevent stent thrombosis. While treatment interruption is contraindicated, substituting one platelet inhibitor for another is one of the treatment alternatives available for patients who develop HSR. However, clopidogrel has the potential for allergic cross-reaction with ticlopidine and prasugrel $(117,118,132,156)$ due to a similar molecular structure. Cheema et al. observed a high level of cross-reactivity in a sample of 42 immediate-onset clopidogrel HSR patients $(23.8 \%$ with ticlopidine, $16.7 \%$ with prasugrel and $7.1 \%$ with both) (118).

Cross-reactivity between ticlopidine and clopidogrel is most common, as these two platelet inhibitors have been on the market the longest. Lokhandwala et al. observed a relatively high incidence of cross-reactivity among patients who switched to ticlopidine following clopidogrel HSR (14 of 52 (26.9\%) patients) (123). In instances of cross-reactivity, the type of ADR developed while receiving ticlopidine was similar to the initial ADR that prompted clopidogrel discontinuation (123). Switching to ticlopidine led to reoccurrence of rash in two patients who have interrupted clopidogrel treatment due to this ADR. Ticlopidine was interrupted as well, while one patient redeveloped the rash after reinitiating clopidogrel treatment (133). It is also interesting to note that no matter which thienopyridine is taken first, cross-reactivity with other thienopyridines can occur.

An additional downside of switching clopidogrel with ticlopidine is the more extensive toxicity profile associated with the latter. For example, the use of ticlopidine is not recommended in patients who develop severe hematological ADRs while on clopidogrel, or in patients with baseline hematological abnormalities (117). Ticlopidine was welltolerated in the short term, yet it was not recommended in a 77 year-old woman with a history of clopidogrel rash and pre-existing neutropenia (151). Another case report of crossreactivity describes a 58 year-old man who was switched to ticlopidine following the development of clopidogrel rash, yet developed severe diarrhea while taking the first generation thienopyridine (146). There are also reports in which ticlopidine was safely substituted in place of clopidogrel. Ticlopidine was administered safely in place of clopidogrel in two patients with clopidogrel cutaneous HSR $(148,149)$. Tolerance to ticlopidine was observed in an 81 year-old male patient with clopidogrel generalized pruritus, erythema and desquamation (143). 
Guidelines for managing patients with UA/NSTEMI or STEMI from the American College of Cardiology Foundation/American Heart Association recommend prasugrel as an alternative to clopidogrel (157). Knowledge about cross-reactivity between clopidogrel and prasugrel is more limited, due to exclusion from prasugrel clinical trials of patients with a history of drug allergy to ticlopidine and/or clopidogrel (117). It is still relatively soon to observe allergic reactions and cross-reactivity with this third generation thienopyridine, even though some cases of prasugrel HSR are reported in the literature. For example, Raccah et al. describe a case of prasugrel rash in a patient with a history of clopidogrel itching cutaneous rash (155). On the other hand, clopidogrel was well-tolerated and efficient in a patient with prasugrel-induced drugHSR and a history of clopidogrel treatment. Interestingly, this patient has previously shown poor response to clopidogrel (156). Prasugrel was well-tolerated in two patients with an allergic reaction to clopidogrel $(145,152)$. Both prasugrel and ticlopidine were well-tolerated in a patient with a history of clopidogrel Stevens-Johnson syndrome (158). However, cases of StevensJohnson syndrome are rarely reported in relation to clopidogrel (159), whereas toxic epidermal necrosis was not associated with clopidogrel use (160).

As thienopyridines have been shown to provoke similar types of ADRs, clopidogrel could be switched with a different class of platelet inhibitors, such as ticagrelor. However, this cyclopentyl triazolopyrimidine antiplatelet agent is relatively new, and even though cases of ticagrelor HSR have not yet been reported, the possibility of cross-reactivity with the older thienopyridines cannot be ruled out.

\section{c. Desensitization Protocols}

Premature discontinuation of antiplatelet treatment following stent implantation is recognized as the main risk factor for developing thrombotic events, particularly stent thrombosis (4, 117, 155, 161). For instance, Iakovou et al. showed that $29 \%$ of patients who discontinued their treatment prematurely after drug eluting stent implantation develop stent thrombosis (162). This is particularly problematic in the days immediately following stent implantation, which coincides with the time frame in which most drug-associated HSR cases occur (151). Higher rates of rehospitalization, coronary stent thrombosis and mortality have been associated with clopidogrel non-adherence and discontinuation (4). Moreover, this treatment often concerns elderly patients ( $\geq 65$ years-old). Elderly patients may experience changes in their capacity to metabolize drugs (renal, hepatic, physiological and/or pathological dysfunction). In addition, due to polymedication, the frequency of ADRs is higher in this population than it is in younger individuals $(121,163)$. Around $40 \%$ of patients $\geq 65$ years of age usually take more than five drugs. Therefore it is difficult to monitor their treatment, and polymedication is recognized as a risk factor for developing ADRs (164). Furthermore, the potential for cross-reactivity among chemically-related thienopyridines described in the previous section highlights the need for an alternative avenue to deal with clopidogrel HSR. To avoid such consequences, some physicians may decide to practice desensitization on patients with clopidogrel cutaneous HSR (excluding Stevens-Johnson syndrome/toxic epidermal necrolysis). Desensitization is recommended in patients with cutaneous HSR symptoms to clopidogrel, in which no treatment alternative is available. Different protocols are being tested.

Desensitization is possible since allergic clopidogrel cutaneous HSRs are immunoglobulin E (IgE)-mediated $(135,139,153)$. Camara and Almeda describe a protocol inspired from antibiotic desensitization, using escalating doses of clopidogrel $(0.005-75 \mathrm{mg})$ administered at 30 min intervals (135). This desensitization protocol was used successfully in 3 patients with clopidogrel cutaneous HSR and ticlopidine intolerance (135). Walker et al. describe a similar desensitization protocol using escalating doses of clopidogrel, administered at 15 min intervals, with doses between 0.02-45 $\mathrm{mg}$ (165). The full dose of $75 \mathrm{mg}$ is administered the following day. Patients are monitored for HSR symptoms. Ticlopidine is not considered a viable alternative due its relatively poor safety profile and high degree of cross-reactivity to clopidogrel (165). Clopidogrel desensitization over a $7 \mathrm{~h}$ period using doses from $0.005 \mathrm{mg}$ to the full $75 \mathrm{mg}$ tablet was successful in a cohort of 24 patients with clopidogrel HSR. The allergic reaction persisted in 4 patients during the desensitization period. However, desensitization was successful in all 24 patients, with 2 patients requiring repeat desensitization (166). Doses between 0.005-75 $\mathrm{mg}$ were administered over a $7 \mathrm{~h}$ interval in two other patients with clopidogrel cutaneous HSR $(139,144)$.

Doses between 0.0005-75 $\mathrm{mg}$ were administered over an $8 \mathrm{~h}$ interval in a patient with clopidogrel rash and ticlopidine intolerance (146). Fajt and Petrov (138) describe a similar 
desensitization protocol, in which the patient is allowed to go home between sessions, over a 2-3 days period. The protocol involves increasing doses of clopidogrel being administered in solution (138). Another patient was successfully desensitized to both aspirin and clopidogrel, using escalating doses, after developing similar cutaneous HSR to both drugs (150).

Because prasugrel allergy is also IgEmediated, prasugrel desensitization was performed in a patient with generalized pruritic maculopapular eruption, using escalating doses ranging from $0-60 \mathrm{mg}$ administered at $30 \mathrm{~min}$ intervals over a period of $7 \mathrm{~h}$. The patient was subsequently able to tolerate prasugrel (153).

\section{d. Suppressive Therapy with Corticosteroids and Antihistamines}

Short-course corticosteroids and antihistamines can be used to create physiological tolerance in patients with clopidogrel HSR, thereby preventing drug discontinuation in this population (132). A wash out period is often necessary in patients undergoing clopidogrel desensitization, yet it is undesirable. Cheema et al. observed a resolution rate of $95.2 \%$ after a mean period of 5 days since initiating prednisone treatment $(30 \mathrm{mg}$ /day for 5 days, followed by doses decreasing every 3 days for 15 days) in a cohort of 62 cutaneous clopidogrel HSR patients. Diphenhydramine (25$50 \mathrm{mg} \mathrm{3-4} \mathrm{times/day)} \mathrm{was} \mathrm{used} \mathrm{in} \mathrm{patients} \mathrm{with}$ pruritus (118).

Use of antihistamines and steroids is recommended only in cutaneous clopidogrel HSR in patients treated with dual aspirin plus clopidogrel therapy (136). Prednisone $(30 \mathrm{mg}$ /day for 5 days) and chlorpheniramine $(4 \mathrm{mg} 3$ times/day for 7 days) is the standard treatment used. Resolution is noted after an average of 3.2 days, usually with $\geq 90.0 \%$ resolution and continuation of clopidogrel treatment (136). Campbell et al. used corticosteroids and antihistamines in 25 patients with clopidogrel HSR developed after PCI. Suppressive therapy allowed symptoms resolution without treatment discontinuation in $22(88.0 \%)$ patients (132). The importance of these studies is that short-course corticosteroids and antihistamines allow the management of clopidogrel HSR without treatment interruption, providing protection against CV adverse events (118, 132, 136, 155, 161).

Steroids and antihistamines led to improvement of clopidogrel cutaneous HSR (142, $147,148)$, as well as prasugrel rash symptoms (155). Intravenous solumedrol and antihistamines were administered in a patient with clopidogrel maculopapular urticarial rash in which previous treatment with prednisone and antihistamines did not achieve relief from HSR symptoms (149). Intravenous methylprednisolone and antihistamines were also successfully used in a patient with clopidogrel erythematous papular rash who was initially unresponsive to antihistamines (140). Symptoms persisted for over 2 weeks despite corticosteroids and antihistamine treatment in a patient with erythematous and pruriginous symptoms (143). In a separate report, additional antihistamines were successful in treating pruritus in a patient who previously underwent partially successful clopidogrel desensitization with escalating doses of the drug (166).

\section{e. Alternatives: The Lymphocyte Toxicity Assay}

The lymphocyte toxicity assay (LTA) is an in vitro test that can be used to diagnose and predict drug HSR (167). This laboratory tool is based on the principle that human lymphocytes in vitro mimic functional cells in vivo. Therefore, lymphocytes from patients with a suspected HSR can be used as surrogate target cells for safe in vitro re-challenge. The LTA can be used to test toxicity of individual drugs, as well as additive effects of other pharmaceutical agents that might be prescribed together with or in place of the incriminated drug, thus uncovering potential drug-drug interactions or cross-reactivity. These cells are suitable as they possess the patient's genotype and express phenotypic variability in drug detoxification enzymes (116, 131, 167-170). Reactive metabolites of the drug believed to have caused the HSR can lead to mitochondrial damage and cellular apoptosis in susceptible patients. This assay measures drug toxicity in terms of cell viability, based on the reduction of the yellow MTT [3-(4,5-dimethylthiazol-2-yl)-2,5-diophenyl tetrazolium bromide] to a purple MTT formazan product by the mitochondria-specific succinate dehydrogenase, an indicator of mitochondrial function (167). Our laboratory has been performing LTAs for over 20 years, validating this technique for numerous anticonvulsants including carbamazepine, phenytoin, zonisamide and phenobarbital, as well as non-steroidal antiinflammatory drugs and sulfonamide antibiotics (116, 131, 167, 169-171). Moreover, our laboratory is in the process of performing LTA on clopidogrel patients, with the hope of safely diagnosing clopidogrel HSR, as well as checking for potential prasugrel or ticagrelor crossreactivity (Neuman MG, unpublished data). Once a drug is identified as the culprit agents using the 
diagnostic potential of the LTA, a safe alternative can be found using the assay's predictive power.

\section{f. Drug Induced Liver or Renal Hypersensitivity}

Although the most common clopidogrel HSRs comprise of cutaneous manifestations, some studies report HSR-associated hepatic toxicity and renal toxicity. Elevated hepatic enzyme levels (usually aspartate aminotransferase (AST) and alanine aminotransferase (ALT)) and high fever have been reported in relation to clopidogrel use. Chills and white blood cell increases have been observed. Abnormal liver function is observed in approximately $3 \%$ of patients receiving clopidogrel $(42,172)$. In most of these cases, improvement in liver transaminase levels and return to liver function baseline is observed upon clopidogrel discontinuation. The onset of symptoms is often reported within the first week of treatment (mean time 5 days) (118). Goyal et al. report the case of an elderly patient who developed hepatocellular injury and cholestatic jaundice 3 weeks after starting clopidogrel treatment (173). The patient experienced AST (179 U/L), ALT (234 U/L), alkaline phosphatase $(1011 \mathrm{U} / \mathrm{L})$ and total bilirubin $(7.3 \mathrm{mg} / \mathrm{dl})$ elevations, as well as anemia and basal metabolic panel disruptions, but no hepatosplenomegaly (173). In vitro tests suggest $\mathrm{T}$ cells involvement in cholestatic hepatitis. Transient eosinophilia observed in two ticlopidine patients supports this hypothesis (174).

Tholl et al. report the case of a 46-year-old with MI who developed membranous nephropathy (stage II) without glomerular or tubule-interstitial scarring after 2 months of treatment with clopidogrel (175). His initial treatment included ticlopidine in combination with aspirin. All medication was stopped after GI complaints were reported, and clopidogrel was introduced after 16 months. Clopidogrel provoked non-selective proteinuria (11.5 g/day) with decreased creatine clearance (106 $\left.\mathrm{mL} / \mathrm{min} / 1.73 \mathrm{~m}^{2}\right)$ and increased $\operatorname{IgE}(140 \mathrm{U} / \mathrm{mL})$ and serum protein $(45 \mathrm{~g} / \mathrm{day}$, containing $20 \mathrm{~g} / \mathrm{L}$ albumin) (175).

A case of drug-induced HSR with fever $\left(38.1^{\circ} \mathrm{C}\right)$ with elevated leukocytes $7.23 \times 10^{9} / \mathrm{L}$ (eosinophils $2.4 \%$ ) and abnormal liver enzyme levels is describes after prasugrel $(60 \mathrm{mg} \mathrm{LD} / 10$ mg MD) exposure in a patient with a history of clopidogrel treatment (156). The patient's fever persisted by day 23, while liver enzyme levels remained elevated. By this time, the leukocyte count returned within normal limits, yet the patient developed eosinophilia (eosinophils 9.7\% at day 19). Symptoms improved following replacement of prasugrel with clopidogrel (156).

\section{g. Hypersensitivity Syndrome Reaction and Viruses}

Drug HSR has been been associated with transient immunosuppression, leading to reactivation of latent or opportunist viruses. Ghosh and Bandyopadhyay describe a human immunodeficiency virus (HIV)-negative 49 yearold woman presenting with hemorrhagic herpes zoster virus lesions during treatment with clopidogrel, and believe that clopidogrel caused thrombocytopenia, which in turn was responsible for the hemorrhagic herpes zoster virus lesions (176).

\section{VI) Drug Interactions}

Platelet inhibitors take part in drug-drug interactions as results of enzyme induction or inhibition, particularly as the target population of this type of medication is generally polymedicated (163). The main classes of drugs involved in drug-drug interactions with platelet inhibitors are PPIs, statins, CCBs and antibiotics. Interactions with HIV antiretroviral drugs are briefly touched upon.

\section{a. Proton Pump Inhibitors}

Long-term dual-therapy with aspirin and platelet inhibitors has the potential to cause GI bleeding. For this reason, PPIs and $\mathrm{H} 2$ antagonists are commonly administered in patients treated with platelet inhibitors. In particular, PPIs offer longlasting inhibition of gastric acid production (31, 177). These drugs are generally recognized as CYP2C19 inhibitors, an enzyme involved in clopidogrel metabolism $(178,179)$. PPIs and clopidogrel will thus compete for the same drugmetabolizing enzyme, such that PPIs may alter the metabolism of the thienopyridine and the bioavailability of its active metabolite, leading to a higher risk of developing $\mathrm{CV}$ adverse events (179). The main PPI involved in drug-drug interactions with clopidogrel is the CYP2C19 inhibitor omeprazole, while an interaction with esomeprazole was also noted. Clopidogrel patients are advised to avoid these agents (31, 124). Several studies have assessed the consequences of combining PPIs with clopidogrel, often with contrasting results.

The combination of clopidogrel and either omeprazole or esomeprazole was associated with a significantly higher risk of developing new $\mathrm{CV}$ adverse events in a case-control study, compared to clopidogrel alone (179). Similarly, a recent meta-analysis showed the potential for increased 
rates of $\mathrm{CV}$ adverse events and $\mathrm{MI}$ in patients taking concomitant clopidogrel and PPIs, with an increase in mortality. However, a high degree of heterogeneity was noted in the reviewed data (180). Use of PPIs following acute MI was associated with reinfarction in a large populationbased nested case-control study. However, this was observed only for PPIs with CYP2C19 inhibitory potential, while the use of pantoprazole, a PPI that is not a substrate of CYP2C19, had no significant effect (181). In the PRINCIPLE-TIMI 44 trial, concomitant use of high-dose clopidogrel and PPIs was associated with a lower mean IPA compared to no PPI use in a relatively small sample. No interaction was found between PPIs and prasugrel (182). Furthermore, the interaction between PPIs and clopidogrel or prasugrel was deemed not significant in terms CV death, non-fatal myocardial infarction, or non-fatal stroke in the TRITON-TIMI 38, suggesting that concomitant treatment with PPIs and thienopyridines is acceptable in patients requiring it (182).

Omeprazole and esomeprazole decrease the efficacy and safety of clopidogrel (179). A metabolic interaction between clopidogrel and the strong CYP2C19 inhibitor omeprazole was shown in a sample of healthy individuals, with the PPI $(80 \mathrm{mg})$ decreasing the $\mathrm{AUC}_{0-24 \mathrm{~h}}$ of clopidogrel's active metabolite by $40 \%$ when administered concomitantly, by $47 \%$ when administered $12 \mathrm{~h}$ apart, by $41 \%$ when a double clopidogrel dose (600 mg LD/150 mg MD) was used and by $14 \%$ when pantoprazole was used instead of omeprazole. The maximal platelet aggregation induced by $5 \mu \mathrm{mol} / \mathrm{L}$ ADP was significantly increased (183). Omeprazole further decreases the IPA of clopidogrel by $21 \%$ when clopidogrel was administered at MD (27) and increases the rate of clopidogrel non-responsiveness (184). Lanzoprazole decreased the $\mathrm{C}_{\max }$ of prasugrel's active metabolite by $29 \%$. AUC and $\mathrm{T}_{\max }$ of the active compound were not altered (29). Pantoprazole was shown to interfere with clopidogrel metabolism to a lesser degree, and it could thus be used as a safer alternative $(10,35)$. Pantoprazole had no effects on the pharmacokinetic profiles of clopidogrel and its active metabolite (183).

In contrast, the rate of major $\mathrm{CV}$ adverse events was found to be comparable between patients not exposed to PPIs and patients exposed to either omeprazole, esomeprazole, lansoprazole, pantoprazole or rabeprazole in 4 separate cohorts of clopidogrel patients compared to clopidogel use alone $(185,186)$. Similarly, use of PPIs was not associated with serious $\mathrm{CV}$ diseases in another large cohort study. Interestingly, only a small fraction of this population was co-exposed to the CYP2C19 inhibitor omeprazole, while the majority of patients took pantoprazole (187).

The clinical relevance of these findings remains debatable. Evidence of an interaction is based mostly on in vitro tests, while clinical studies frequently report contrasting outcomes, often based on the interaction between clopidogrel and PPIs as a whole (188). Nonetheless, some studies show that only specific PPIs interact with thienopyridines. Furthermore, PPIs themselves were found to have either harmful, neutral or protective effects in terms of $\mathrm{CV}$ adverse events, independent of clopidogrel use, which may further confound results (185, 189). High dose $\mathrm{H} 2$ antagonists are an alternative to PPIs that can be used to avoid drug-drug interactions with other CYP2C19 substrates (178).

\section{b. Statins}

Statins are a class of anti-cholesterol agents commonly used to reduce morbidity and mortality after coronary stent implantation, owing to their anti-inflammatory, anti-oxidative and antithrombotic properties $(190,191)$. CYP3A4 plays a major role in the metabolism and elimination of the lipophilic atorvastatin and simvastatin. As an inhibitor of CYP3A4, atorvastatin can inhibit clopidogrel metabolism in a dose-dependent manner, leading to insufficient platelet inhibition and an increased risk of CV adverse events (184). A similar interaction is not observed with hydrophilic statins, as they are not significant CYP3A4 substrates $(10,184)$. Thus, prescribing clopidogrel in combination with atorvastatin is contraindicated (10).

However, the possible interaction between clopidogrel and statins is controversial. Atorvastatin reduced the IPA of clopidogrel with $300 \mathrm{mg}$ LD but not with $600 \mathrm{mg} \mathrm{LD}$, while the effect of CYP3A4 polymorphism is unknown (184). Several ex vivo studies suggest that the use of statins, in particularly atorvastatin (192-194), simvastatin (194, 195) and fluvastatin (195), decreases the effect of clopidogrel, particularly during the loading phase. At the same time, other studies did not find interactions between clopidogrel and atorvastatin (195, 196), pravastatin (195, 196), rosuvastatin (195), simvastatin (196) or fluvastatin (196). Furthermore, atorvastatin does not interfere with the pharmacokinetics of prasugrel (35). On the other hand, ticagrelor increases the $\mathrm{C}_{\max }$ of simvastatin by $81 \%$ and its AUC by $56 \%$ (30). 
Nonetheless, hydrophilic statins present a safer alternative.

\section{c. $\mathrm{Ca}^{+2}$ Channel Blockers}

$\mathrm{CCBs}$ are often used to treat hypertension. Coadministration of these CYP3A4 substrates together with platelet inhibitors creates the potential for drug-drug interactions, decreasing responsiveness to the latter class (184). Once again, this is a controversial topic, as evidence is often contradictory. Co-administration of the moderate CYP3A4 inhibitor diltiazem increases the $\mathrm{C}_{\max }$ of ticagrelor by $69 \%$ and its AUC by $2.7-$ fold, while decreasing the $\mathrm{C}_{\max }$ of the active metabolite by $38 \%$ with no changes in its AUC (30). An ex vivo study on platelet function showed that CCBs can interfere with clopidogrel metabolism, leading to reduced levels of the active metabolite and impaired platelet inhibition (197). Decreased response to clopidogrel following co-administration of $\mathrm{CCBs}$ is also reported elsewhere $(198,199)$. On the other hand, no evidence was found that CCBs decrease the efficacy of clopidogrel one year after PCI in the CREDO trial (197). Based on these findings, Schmidt et al. suggest that co-administration of clopidogrel and $\mathrm{CCBs}$ is safe in patients undergoing PCI (200).

\section{d. Antibiotics}

Co-administration of the strong CYP3A4 inhibitor ketoconazole, a synthetic antifungal drug, is associated with a 2.4-fold increase in ticagrelor $\mathrm{C}_{\max }$ and a 7.3-fold increase in AUC, while the $\mathrm{C}_{\max }$ for the active metabolite was decreased by $89 \%$ and the AUC by $56 \%$ (30). Srinivasan and Smith describe the case of a male patient who developed suspected clopidogrel resistance following co-administration of the platelet inhibitor, aspirin and antimycobacterial treatment including rifampicin (CYP3A4 inducer), ethambutol and clarithromycin (CYP3A4 inhibitors) (201). The patient developed stent thrombosis within five days of treatment initiation, and it was hypothesized that these drug-drug interactions can reduce clopidogrel efficacy and induce resistance (201). There was also less exposure to the clopidogrel active metabolite and a subsequent reduction in IPA when ketoconazole was co-administered with clopidogrel (99).

\section{e. Human Immunodeficiency Virus Antiretroviral Drugs}

$\mathrm{CV}$ diseases are of concern for HIV-infected patients, as they represent more than $10 \%$ of deaths in this population (202). A possible drug- drug interaction was uncovered in vitro between prasugrel and ritonavir, a potent CYP3A4 and 2B6 inhibitor. However, more work is needed to evaluate long-term clinical risks (203).

\section{VII) Poor Responsiveness: Evidence and Perspectives}

In order to assess clopidogrel resistance, reliable assays that provide sufficient predictive value are needed. Platelet function testing and genetic testing can be used to identify individuals at risk of developing CV adverse events and to facilitate treatment changes. The mechanism of clopidogrel resistance involves modifications in the pharmacokinetics and pharmacodynamics of this drug. Therefore, it is important to monitor these data.

\section{a. Personalized Medicine}

The goals of personalized medicine are to maximize the therapeutic effects of a drug, while minimizing its toxicity (204). Personalized medicine is defined as the practice of tailoring therapeutic intervention to a patient's disease, demographic characteristics, genetics, environment, lifestyle and health status (205). There are many tools that allow physicians to uncover those factors that distinguish one individual for another, among which pharmacogenomics testing is of paramount importance. Dosing based on one's pharmacokinetic profile, as well as therapeutic drug monitoring (TDM), are other examples (204).

\section{b. Therapeutic Drug Monitoring}

The two main clinical reasons for which pharmacological responses to platelet inhibitors should be measured are that an insufficient inhibition of platelet function may result in atherothrombotic complications such as thromboembolic events, while excessive IPA may lead to bleeding complications. For these reasons, the appropriate identification of resistant or poor responders to platelet inhibitors remains challenging in the clinical practice. TDM may help facilitate these challenges. It requires knowledge about the patient's pharmacokinetic and pharmacodynamic profiles in order to assess the factors that mediate drug exposure (204). Specifically, a priori TDM is designed to prescribe the most adequate starting dose based on knowledge about the patient's pharmacokinetic and pharmacodynamic profiles, while a posteriori TDM assesses the adequacy of drug dosing based on measurements of drug concentration ranges in 
blood or plasma (204). This section will provide a brief overview of the analytical tools that are used to measure plasma levels of platelet inhibitors and their metabolites. These measurements are used mainly for pharmacodynamic and pharmacokinetic determination. Pharmacodynamic measurements involve the examination of residual platelet function following drug administration. While thienopyridines require metabolic activation to exert their antiplatelet effect, both ticagrelor and its active metabolite possess pharmacological properties. Therefore, measuring both ticagrelor parent compound and active metabolite will have different implications for drug interactions.

Drug resistance, including resistance to antiplatelet drugs, defines a state in which the drug is unable to reach its pharmacological target (206). For this reason, laboratory methods used to evaluate the effects of antiplatelet drugs should be designed to measure the direct pharmacodynamic effect of a drug, rather than its consequences for global platelet function (206, 207). Based on pathophysiological, pharmacological and practical considerations, it seems logical to assess pharmacological inhibition of platelet function in terms of ADP agonist-induced platelet aggregation. As a result, responses induced by $\mathrm{TXA}_{2}$ or arachidonic acid (light transmission aggregometry, whole-blood aggregometry) should be measured to assess the effects of aspirin, while vasodilator stimulated phosphoprotein (VASP) using flow cytometry or ADP-induced responses using light transmission aggregometry, wholeblood aggregometry, and possibly flow cytometry, should be measured for the detection of clopidogrel actions. However, it should be noted that while serum $\mathrm{TXA}_{2}$ levels $<2 \mathrm{ng} / \mathrm{ml}$ reflect aspirin-induced inhibition of COX-1 activity with high sensitivity, VASP exhibits a wide variability upon treatment with clopidogrel or prasugrel.

Most of these methods use a liquid chromatography/tandem mass spectrometry (LC/MS/MS) positive electrospray ionization method for the assay of clopidogrel in human plasma. Nirogi et al. separated the analytes using an isocratic mobile phase on a reversed-phase column and analyzed their products by MS with a linear dynamic range of $5-6000 \mathrm{pg} / \mathrm{mL}$ (208). Shin and Yoo described an LC/MS/MS assay validated to be linear over a concentration range of $10-10000 \mathrm{pg} / \mathrm{mL}$ (209). Clopidogrel was extracted by single liquid-liquid extraction with pentane, followed by chromatographic separations on a $\mathrm{C}_{18}$ column (209). Subsequently, Takahashi et al. also measured clopidogrel and its active metabolite in human plasma by LC/MS/MS, using the alkylating reagent 2-bromo-3'methoxyacetophenone to stabilize the thiol groupcontaining active metabolite (38). An analog of the derivatized clopidogrel active metabolite was used as the internal standard. The calibration curve ranged between $0.5-250 \mathrm{ng} / \mathrm{mL}$ (38).

Farid et al. developed LC/MS/MS assays to quantify the active and three inactive metabolites of prasugrel (210). The analytes were detected and quantified with a triple quadrupole MS using positive electrospray ionization. The concentration range was $1-500 \mathrm{ng} / \mathrm{mL}$ for the inactive metabolites and $0.5-250 \mathrm{ng} / \mathrm{mL}$ for the active metabolite. Derivatization of the active metabolite in blood with 2-bromo-3'methoxyacetophenone immediately after collection was essential to ensure the stability of the metabolite during sample processing and storage (210). Sillén et al. reported the pharmacokinetic analysis of ticagrelor employing LC/MS/MS (211). Teng and Butler reported the disposition and metabolism of ticagrelor in six healthy volunteers, using a single oral dose of ${ }^{14} \mathrm{C}$ radiolabeled ticagrelor $(200 \mathrm{mg}$ ticagrelor as a 10 g suspension, $222.7 \mathrm{kBq} / \mathrm{g}$ ) (212). Blood samples, for the purpose of measuring total radioactivity in whole blood and plasma of ticagrelor and in plasma for its active metabolite AR-C124910XX, were collected pre-dose and at various time points up to $36 \mathrm{~h}$ post-dose. Total ${ }^{14} \mathrm{C}$ radioactivity was determined by liquid scintillation counting in whole blood and plasma, with $25 \mathrm{dmp}$ above background set as the limit of detection. In addition, ticagrelor and its metabolite concentrations in urine and plasma were analyzed using LC/MS/MS, with assay lower limits of quantification of $5.0 \mathrm{ng} / \mathrm{mL}$ for ticagrelor and 2.5 $\mathrm{ng} / \mathrm{mL}$ for AR-C124910XX in plasma (212).

Light transmission aggregometry is the principal assay designed to assess clopidogrel resistance, which measured platelet aggregation in response to $20 \mu \mathrm{mol} / \mathrm{L}$ ADP stimulation. Residual platelet aggregation in excess of $50 \%$ of the baseline level is considered to predict clopidogrel resistance. The main limitation of this assay is that it provides no indication of the clinical tendency of the patient to develop thrombosis (93). In contrast, the point-of-care platelet function test offers more valuable information. This assay measures agglutination of fibrinogencoated beads mixed with whole blood in response to ADP stimulation (213). The VASP platelet reactivity index, an assay designed to measure P2 $\mathrm{Y}_{12}$ activity, measures by flow calorimetry the activity of the VASP protein, which becomes phosphorylated in the presence of $\mathrm{P}_{2} \mathrm{Y}_{12}$ 
stimulation. This assay has been successfully used to personalize the clopidogrel dose for improved clinical outcome (214). A modified Thrombelastograph assay provides continuous assessment of platelet function (215). However, these tests are not routinely recommended in patients undergoing PCI due to a relative lack of evidence. Such tests should be considered only if a patient is known to be at high risk of clopidogrel ADRs or resistance (93). Anderson et al. argue that a better way to follow the absorption and the metabolism of clopidogrel is to measure the $\mathrm{C}_{\max }$ of the drug or its active metabolite (97).

\section{CONCLUSION}

Platelet inhibitors are common treatments for ACS patients. Thienopyridine drugs are widely used, particularly clopidogrel. However, the complex pharmacogenetic and pharmacokinetic profiles of clopidogrel lead to interindividual variability, which can increase the incidence of ADRs, including HSR. To overcome those issues, switching to alternative medicine or desensitization protocols can be considered. Even though not routinely used, genetic tests and platelet function assays can be particularly beneficial for high-risk patients or for those who have already developed an ADRs, as they can help predict tolerability and response to treatment. Newer drugs like prasugrel and ticagrelor present fewer problems, owing to their simpler mechanisms of activation and action. Both of these drugs have demonstrated better efficacy than clopidogrel, and even though they have a slightly less favorable safety profile, they are overall associated with better outcomes in ACS patients. New antiplatelet agents, such as the $\mathrm{P}^{2} \mathrm{Y}_{12}$ inhibitors cangrelor and elinogrel, are tested (216), the latter of which was discontinued due to an unfavorable safety profile.

Preventable ADRs carry a substantial risk of morbidity and even mortality to the patient, while placing a high financial burden on the health system (217). Therefore, ACS patients receiving concomitant treatment with platelet inhibitors and other medication should be closely monitored for ADRs, drug-drug interactions and loss of drug efficacy. It thus becomes essential that the right drugs are administered to the right patients in order to avoid complications. Laboratory assays and in vitro tools provide useful methods to monitor medication efficacy and toxicity. While clinical trials provide valuable information about common ADRs, it remains vitally important that rare ADRs and drug-drug interactions are reported and make their way into pharmacovigilance databases, where they become available for health care providers and patients alike. TDM can help identify the patients who would benefit most from alternative treatments and personalized medicine.

\section{CONFLICT OF INTEREST}

The authors have no conflict of interest to declare and have contributed equally in this research.

\section{ACKNOWLEDGMENTS}

The review was performed during the summer 2012 with the financial support of "In Vitro Drug Safety and Biotechnology".

\section{REFERENCES}

1. Public Health Agency of Canada. Tracking Heart Disease and Stroke in Canada, 2009. Last accessed Aug 23 2012. http://www.phacaspc.gc.ca/publicat/2009/cvd-avc/pdf/cvd-avs2009-eng.pdf.

2. Fox KA, Birkhead J, Wilcox R, Knight C, Barth J. British Cardiac Society Working Group on the definition of myocardial infarction. Heart, 2004; 90:603-609.

3. Canadian Institute for Health Information. Health Indicators, 2010. Last accessed Sept 202012. https://secure.cihi.ca/free products/Healthindicat ors2010_en.pdf.

4. Page RL 2nd, Ghushchyan V, Allen RR, Roper L, Beck D, Jonathan BH, Frech-Tamas F, Chan W, McQueen RB, Nair KV. Costs and outcomes associated with clopidogrel discontinuation in Medicare beneficiaries with acute coronary syndrome in the coverage gap. Drug Healthc Patient Saf, 2012; 4:67-74.

5. Institut de Veille Sanitaire. Les cardiopathies ischémiques. Maladies cardio-vasculaires. Maladies chroniques et traumatismes, 2011. Last accessed Aug 232. http://www.invs.sante.fr/Dossiersthematiques/Maladies-chroniques-ettraumatismes/Maladies-cardio-vasculaires/Lescardiopathies-ischemiques.

6. Matusik P, Guzik B, Weber C, Guzik TJ. Do we know enough about the immune pathogenesis of acute coronary syndromes to improve clinical practice? Thromb Haemost, 2012; 108:443-456.

7. Collet JP, Choussat R, Montalescot G. Platelet aggregation and antiplatelet agents in acute coronary syndromes. Med Sci (Paris), 2004; 20:291-297.

8. Levi M, van der Poll T, Büller HR. Bidirectional relation between inflammation and coagulation. Circulation, 2004; 109:2698-2704.

9. Schönberger T, Ziegler M, Borst O, Konrad I, Nieswandt B, Massberg S, Ochmann C, Jürgens T, Seizer P, Langer H, Münch G, Ungerer M, 
Preissner KT, Elvers M, Gawaz MP. The platelet collagen receptor GPVI-Fc reduces platelet adhesion to activated endothelium and preserves myocardial function after transient ischemia in mice. Am J Physiol Cell Physiol, 2012; 303:C757-C766.

10. Précis d'anesthésie cardiaque. Annexe B Les Antiplaquettaires, 2012. Last accessed Aug 23 2012.

http://www.precisdanesthesiecardiaque.ch/Pdf/A nnexe $\% 20 B \% 20$ Antiplaquettaires.pdf.

11. Gawaz M, Langer $H$, May AE. Platelets in inflammation and atherogenesis. J Clin Invest, 2005; 115:3378-3384.

12. Kaplan ZS, Jackson SP. The role of platelets in atherothrombosis. Hematology Am Soc Hematol Educ Program, 2011; 2011:51-61.

13. Jennings LK. Role of platelets in atherothrombosis. Am J Cardiol, 2009; 103:4A$10 \mathrm{~A}$.

14. Ruggeri ZM. Platelets in atherothrombosis. Nat Med, 2002; 8:1227-1234.

15. Langer HF, Gawaz M. Platelet-vessel wall interactions in atherosclerotic disease. Thromb Haemost, 2008; 99:480-486.

16. Mangin P, Yuan Y, Goncalves I, Eckly A, Freund M, Cazenave JP, Gachet C, Jackson SP, Lanza F. Signaling role for phospholipase C gamma 2 in platelet glycoprotein $\mathrm{Ib}$ alpha calcium flux and cytoskeletal reorganization. Involvement of a pathway distinct from $\mathrm{FcR}$ gamma chain and Fc gamma RIIA. J Biol Chem, 2003; 278:32880-32891.

17. Farid NA, Kurihara A, Wrighton SA. Metabolisme and Disposition of the Thienopyridine Antiplatelet Drugs Ticlopidine, CLopidogrel, and Prasugrel in Humans. J Clin Pharmacol, 2010; 50:126-142.

18. Maffrand JP. The story of clopidogrel and its predecessor, ticlopidine: Could these major antiplatelet and antithrombotic drugs be discovered and developed today. Comptes Rendus Chimi, 2012; 15:737-743.

19. Wijeyeratne YD, Heptinstall S. Anti-platelet therapy: ADP receptor antagonists. $\mathrm{Br} \mathrm{J}$ Clin Pharmacol, 2011; 72:647-657.

20. Gurbel PA, Antonino MJ, Tantry US. Recent developments in clopidogrel pharmacology and their relation to clinical outcomes. Expert Opin Drug Metab Toxicol, 2009; 5:989-1004.

21. Nawarskas JJ, Snowden SS. Critical appraisal of ticagrelor in the management of acute coronary syndrome. Ther Clin Risk Manag, 2011; 7:473488.

22. Teng R, Oliver S, Hayes MA, Butler $\mathrm{K}$. Absorption, distribution, metabolism, and excretion of ticagrelor in healthy subjects. Drug Metab Dispos, 2010; 38:1514-1521.

23. Zhou D, Andersson TB, Grimm SW. In vitro evaluation of potential drug-drug interactions with ticagrelor: cytochrome $\mathrm{P} 450$ reaction phenotyping, inhibition, induction, and differential kinetics. Drug Metab Dispos, 2011; 39:703-710.

24. Giorgi MA, Cohen Arazi H, Gonzalez CD, Di Girolamo G. Beyond efficacy: pharmacokinetic differences between clopidogrel, prasugrel and ticagrelor. Expert Opin Pharmacother, 2011; 12:1285-1295.

25. North West London Cardiac Network. Guidance for Prescribing Clopidogrel. 2007. Last accessed Sept $\quad 172012$. http://www.nwlcn.co.uk/pdfs/clopidogrelreportja n08ratifiedbyboard.pdf.

26. New Guidelines for Outpatient Antiplatelet Therapy in Canada Highlights from the Canadian Cardiovascular Congress, Montreal, October 2010. The Canadian Journal of Diagnosis, 2010; 27:29-36.

27. European Medicines Agency. Summary of Product Characteristics - Clopidogrel. Last $\begin{array}{llll}\text { accessed } & \text { Sept } & 18 & \end{array}$ http://www.ema.europa.eu/docs/en_GB/documen t_library/EPAR -

Product_Information/human/001134/WC50002 9504.pdf.

28. Drug Information Portal. Ticlid (Ticlopidine) Indications and Dosage. Last accessed Sept 18 2012.

http://www.druglib.com/druginfo/ticlid/indicatio ns_dosage/.

29. European Medicines Agency. Summary of Product Characteristics - Efient. Last accessed Sept $18 \quad 2012$. http://www.ema.europa.eu/docs/en_GB/documen t_library/EPAR_-

_Product_Information/human/000984/WC50002 1971.pdf

30. European Medicines Agency. Summary of Product Characteristics - Brilique. Last accessed Sept $18 \quad 2012$. http://www.ema.europa.eu/docs/en_GB/documen t library/EPAR -

_Product_Information/human/001241/WC50010 0494.pdf

31. Agence Nationale de Sécurité du Médicament et des Produits de Santé. Recommandations - Bon Usage des Agents Antiplaquettaires. 2012. $\begin{array}{llll}\text { Accessed } & \text { Sept } & 18 & \end{array}$ http://www.sfmu.org/documents/consensus/Reco -Antiplaquettaires-argumentaire $\% 20$ final2012.pdf.

32. Yoneda K, Iwamura R, Kishi H, Mizukami Y, Mogami K, Kobayashi S. Identification of the active metabolite of ticlopidine from rat in vitro metabolites. Br J Pharmacol, 2004; 142:551-557.

33. Savi P, Pereillo JM, Uzabiaga MF, Combalbert J, Picard C, Maffrand JP, Pascal M, Herbert JM. Identification and biological activity of the active metabolite of clopidogrel. Thromb Haemost, 2000; 84:891-896.

34. Pereillo JM, Maftouh M, Andrieu A, Uzabiaga MF, Fedeli O, Savi P, Pascal M, Herbert JM, Maffrand JP, Picard C. Structure and stereochemistry of the active metabolite of 
clopidogrel. Drug Metab Dispos, 2002; 30:12881295.

35. Compendium of Pharmaceuticals and Specialties. Toronto: Canadian Pharmaceutical Association. 2012.

36. Angiolillo DJ, Fernandez-Ortiz A, Bernardo E, Alfonso F, Macaya C, Bass TA, Costa MA. Variability in individual responsiveness to clopidogrel: clinical implications, management, and future perspectives. J Am Coll Cardiol, 2007; 49:1505-1516.

37. Shah J, Fratis A, Ellis D, Murakami S, Teitelbaum P. Effect of food and antacid on absorption of orally administered ticlopidine hydrochloride. J Clin Pharmacol, 1990; 30:733736.

38. Takahashi M, Pang H, Kawabata K, Farid NA, Kurihara A. Quantitative determination of clopidogrel active metabolite in human plasma by LC-MS/MS. J Pharm Biomed Anal, 2008; 48:1219-1224

39. Bristol-Myers Squibb/Sanofi Pharmaceuticals Partnership. Information about Clopidogrel Bisulfate. 2010. Last accessed Nov 22012. http://www.plavix.com/clopidogrel.aspx.

40. Bristol-Myers Squibb/Sanofi Pharmaceuticals Partnership. Plavix (Clopidogrel Bisulfate) Tablets Prescribing Information. 2011. Last $\begin{array}{llll}\text { accessed } & \text { Nov } & 2 & 2012 .\end{array}$ http://products.sanofi.us/plavix/plavix.html\#secti on-14.1.

41. Small DS, Farid NA, Li YG, Ernest CS 2nd, Payne CD, Salazar DE, Winters KJ. Effect of ranitidine on the pharmacokinetics and pharmacodynamics of prasugrel and clopidogrel. Curr Med Res Opin, 2008; 24:2251-2257.

42. CAPRIE Steering Committee. A randomised, blinded, trial of clopidogrel versus aspirin in patients at risk of ischaemic events (CAPRIE). Lancet, 1996; 348:1329-1339.

43. Yusuf S, Zhao F, Mehta SR, Chrolavicius S, Tognoni G, Fox KK. Effects of clopidogrel in addition to aspirin in patients with acute coronary syndromes without ST-segment elevation. N Engl J Med, 2001; 345:494-502.

44. Gerschutz GP, Bhatt DL. The CURE trial: using clopidogrel in acute coronary syndromes without ST-segment elevation. Cleve Clin J Med, 2002; 69:377-378.

45. Mehta SR, Yusuf S, Peters RJ, Bertrand ME, Lewis BS, Natarajan MK, Malmberg K, Rupprecht H, Zhao F, Chrolavicius S, Copland I, Fox KA. Effects of pretreatment with clopidogrel and aspirin followed by long-term therapy in patients undergoing percutaneous coronary intervention: the PCI-CURE study. Lancet, 2001; 358:527-533.

46. Steinhubl SR, Berger PB, Mann JT 3rd, Fry ET, DeLago A, Wilmer C, Topol EJ. Early and sustained dual oral antiplatelet therapy following percutaneous coronary intervention: a randomized controlled trial. JAMA, 2002; 288:2411-2420.
47. Markus HS, Droste DW, Kaps M, Larrue V, Lees KR, Siebler M, Ringelstein EB. Dual antiplatelet therapy with clopidogrel and aspirin in symptomatic carotid stenosis evaluated using doppler embolic signal detection: the Clopidogrel and Aspirin for Reduction of Emboli in Symptomatic Carotid Stenosis (CARESS) trial. Circulation, 2005; 111:2233-2240.

48. Sabatine MS, Cannon CP, Gibson CM, LópezSendón JL, Montalescot G, Theroux P, Claeys MJ, Cools F, Hill KA, Skene AM, McCabe CH, Braunwald E. Addition of clopidogrel to aspirin and fibrinolytic therapy for myocardial infarction with ST-segment elevation. N Engl J Med, 2005; 352:1179-1189.

49. Sabatine MS, Cannon CP, Gibson CM, LópezSendón JL, Montalescot G, Theroux P, Lewis BS, Murphy SA, McCabe $\mathrm{CH}$, Braunwald E. Effect of clopidogrel pretreatment before percutaneous coronary intervention in patients with ST-elevation myocardial infarction treated with fibrinolytics: the PCI-CLARITY study. JAMA, 2005; 294:1224-1232.

50. Scirica BM, Sabatine MS, Morrow DA, Gibson CM, Murphy SA, Wiviott SD, Giugliano RP, McCabe CH, Cannon CP, Braunwald E. The role of clopidogrel in early and sustained arterial patency after fibrinolysis for ST-segment elevation myocardial infarction: the ECG CLARITY-TIMI 28 Study. J Am Coll Cardiol, 2006; 48:37-42.

51. Chen ZM, Jiang LX, Chen YP, Xie JX, Pan HC, Peto R, Collins R, Liu LS. Addition of clopidogrel to aspirin in 45,852 patients with acute myocardial infarction: randomised placebocontrolled trial. Lancet, 2005; 366:1607-1621.

52. Bhatt DL, Fox KA, Hacke W, Berger PB, Black HR, Boden WE, Cacoub P, Cohen EA, Creager MA, Easton JD, Flather MD, Haffner SM, Hamm CW, Hankey GJ, Johnston SC, Mak KH, Mas JL, Montalescot G, Pearson TA, Steg PG, Steinhubl SR, Weber MA, Brennan DM, Fabry-Ribaudo L, Booth J, Topol EJ. Clopidogrel and aspirin versus aspirin alone for the prevention of atherothrombotic events. N Engl J Med, 2006; 354:1706-1717.

53. Bhatt DL, Flather MD, Hacke W, Berger PB, Black HR, Boden WE, Cacoub P, Cohen EA, Creager MA, Easton JD,Hamm CW, Hankey GJ, Johnston SC, Mak KH, Mas JL, Montalescot G, Pearson TA, Steg PG, Steinhubl SR, Weber MA, Fabry-Ribaudo L, Hu T, Topol EJ, Fox KA. Patients with prior myocardial infarction, stroke, or symptomatic peripheral arterial disease in the CHARISMA trial. J Am Coll Cardiol, 2007; 49:1982-1988.

54. Diener HC, Bogousslavsky J, Brass LM, Cimminiello C, Csiba L, Kaste M, Leys D, Matias-Guiu J, Rupprecht HJ. Aspirin and clopidogrel compared with clopidogrel alone after recent ischaemic stroke or transient ischaemic attack in high-risk patients (MATCH): 
randomised, double-blind, placebo-controlled trial. Lancet, 2004; 364:331-337.

55. Price MJ, Berger PB, Teirstein PS, Tanguay JF, Angiolillo DJ, Spriggs D, Puri S, Robbins M, Garratt KN, Bertrand OF, Stillabower ME, Aragon JR, Kandzari DE, Stinis CT, Lee MS, Manoukian SV, Cannon CP, Schork NJ, Topol EJ. Standard- vs high-dose clopidogrel based on platelet function testing after percutaneous coronary intervention: the GRAVITAS randomized trial. JAMA, 2011; 305:1097-1105.

56. CURRENT-OASIS 7 Investigators, Mehta SR, Bassand JP, Chrolavicius S, Diaz R, Eikelboom JW, Fox KA, Granger CB, Jolly S, Joyner CD, Rupprecht HJ, Widimsky P, Afzal R, Pogue J, Yusuf S. Dose comparisons of clopidogrel and aspirin in acute coronary syndromes. $\mathrm{N}$ Engl $\mathbf{J}$ Med, 2010; 363:930-942.

57. Mehta SR, Tanguay JF, Eikelboom JW, Jolly SS, Joyner CD, Granger CB, Faxon DP, Rupprecht HJ, Budaj A, Avezum A, Widimsky P, Steg PG, Bassand JP, Montalescot G, Macaya C, Di Pasquale G, Niemela K, Ajani AE, White HD, Chrolavicius S, Gao P, Fox KA, Yusuf S. Double-dose versus standard-dose clopidogrel and high-dose versus low-dose aspirin in individuals undergoing percutaneous coronary intervention for acute coronary syndromes (CURRENT-OASIS 7): a randomised factorial trial. Lancet, 2010; 376:1233-1243.

58. Müller C, Büttner HJ, Petersen J, Roskamm H. A randomized comparison of clopidogrel and aspirin versus ticlopidine and aspirin after the placement of coronary-artery stents. Circulation, 2000; 101:590-593.

59. Bertrand ME, Rupprecht HJ, Urban P, Gershlick AH. Double-blind study of the safety of clopidogrel with and without a loading dose in combination with aspirin compared with ticlopidine in combination with aspirin after coronary stenting: the clopidogrel aspirin stent international cooperative study (CLASSICS). Circulation, 2000; 102:624-629.

60. Berger PB. Results of the Ticlid or Plavix PostStents (TOPPS) trial: do they justify the switch from ticlopidine to clopidogrel after coronary stent placement? Curr Control Trials Cardiovasc Med, 2000; 1:83-87.

61. Wiviott SD, Antman EM, Winters KJ, Weerakkody G, Murphy SA, Behounek BD, Carney RJ, Lazzam C, McKay RG, McCabe CH, Braunwald E. Randomized comparison of prasugrel (CS-747, LY640315), a novel thienopyridine P2Y12 antagonist, with clopidogrel in percutaneous coronary intervention: results of the Joint Utilization of Medications to Block Platelets Optimally (JUMBO)-TIMI 26 trial. Circulation, 2005; 111:3366-3373.

62. Angiolillo DJ, Saucedo JF, Deraad R, Frelinger AL, Gurbel PA, Costigan TM, Jakubowski JA, Ojeh CK, Effron MB. Increased platelet inhibition after switching from maintenance clopidogrel to prasugrel in patients with acute coronary syndromes: results of the SWAP (SWitching Anti Platelet) study. J Am Coll Cardiol, 2010; 56:1017-1023.

63. Wiviott SD, Braunwald E, McCabe $\mathrm{CH}$, Montalescot G, Ruzyllo W, Gottlieb S, Neumann FJ, Ardissino D, De Servi S, Murphy SA, Riesmeyer J, Weerakkody G, Gibson CM, Antman EM. Prasugrel versus clopidogrel in patients with acute coronary syndromes. N Engl J Med, 2007; 357:2001-2015.

64. Antman EM, Wiviott SD, Murphy SA, Voitk J, Hasin Y, Widimsky P, Chandna H, Macias W, McCabe $\mathrm{CH}$, Braunwald E. Early and late benefits of prasugrel in patients with acute coronary syndromes undergoing percutaneous coronary intervention: a TRITON-TIMI 38 (TRial to Assess Improvement in Therapeutic Outcomes by Optimizing Platelet InhibitioN with Prasugrel-Thrombolysis In Myocardial Infarction) analysis. J Am Coll Cardiol, 2008; 51:2028-2033.

65. Murphy SA, Antman EM, Wiviott SD, Weerakkody G, Morocutti G, Huber K, LopezSendon J, McCabe CH, Braunwald E. Reduction in recurrent cardiovascular events with prasugrel compared with clopidogrel in patients with acute coronary syndromes from the TRITON-TIMI 38 trial. Eur Heart J, 2008; 29:2473-2479.

66. Wiviott SD, Braunwald E, Angiolillo DJ, Meisel S, Dalby AJ, Verheugt FW, Goodman SG, Corbalan R, Purdy DA, Murphy SA, McCabe $\mathrm{CH}$, Antman EM. Greater clinical benefit of more intensive oral antiplatelet therapy with prasugrel in patients with diabetes mellitus in the trial to assess improvement in therapeutic outcomes by optimizing platelet inhibition with prasugrelThrombolysis in Myocardial Infarction 38. Circulation, 2008; 118:1626-1636.

67. Wiviott SD, Braunwald E, McCabe CH, Horvath I, Keltai M, Herrman JP, Van de Werf F, Downey WE, Scirica BM, Murphy SA, Antman EM. Intensive oral antiplatelet therapy for reduction of ischaemic events including stent thrombosis in patients with acute coronary syndromes treated with percutaneous coronary intervention and stenting in the TRITON-TIMI 38 trial: a subanalysis of a randomised trial. Lancet, 2008; 371:1353-1363.

68. Montalescot G, Wiviott SD, Braunwald E, Murphy SA, Gibson CM, McCabe CH, Antman EM. Prasugrel compared with clopidogrel in patients undergoing percutaneous coronary intervention for ST-elevation myocardial infarction (TRITON-TIMI 38): double-blind, randomised controlled trial. Lancet, 2009; 373:723-731.

69. Smith PK, Goodnough LT, Levy JH, Poston RS, Short MA, Weerakkody GJ, Lenarz LA. Mortality Benefit With Prasugrel in the TRITON-TIMI 38 Coronary Artery Bypass Grafting Cohort: Risk-Adjusted Retrospective 
Data Analysis. J Am Coll Cardiol, 2012; 60:388396.

70. Cannon CP, Husted S, Harrington RA, Scirica BM, Emanuelsson H, Peters G, Storey RF. Safety, tolerability, and initial efficacy of AZD6140, the first reversible oral adenosine diphosphate receptor antagonist, compared with clopidogrel, in patients with non-ST-segment elevation acute coronary syndrome: primary results of the DISPERSE-2 trial. J Am Coll Cardiol, 2007; 50:1844-1851.

71. Storey RF, Husted S, Harrington RA, Heptinstall S, Wilcox RG, Peters G, Wickens M, Emanuelsson H, Gurbel P, Grande P, Cannon CP. Inhibition of platelet aggregation by AZD6140, a reversible oral P2Y12 receptor antagonist, compared with clopidogrel in patients with acute coronary syndromes. J Am Coll Cardiol, 2007; 50:1852-1856.

72. Gurbel PA, Bliden KP, Butler K, Tantry US, Gesheff T, Wei C, Teng R, Antonino MJ, Patil SB, Karunakaran A, Kereiakes DJ, Parris C, Purdy D, Wilson V, Ledley GS, Storey RF. Randomized double-blind assessment of the ONSET and OFFSET of the antiplatelet effects of ticagrelor versus clopidogrel in patients with stable coronary artery disease: the ONSET/OFFSET study. Circulation, 2009; 120:2577-2585.

73. Storey RF, Bliden KP, Patil SB, Karunakaran A, Ecob R, Butler K, Teng R, Wei C, Tantry US, Gurbel PA. Incidence of dyspnea and assessment of cardiac and pulmonary function in patients with stable coronary artery disease receiving ticagrelor, clopidogrel, or placebo in the ONSET/OFFSET study. J Am Coll Cardiol, 2010; 56:185-193.

74. Gurbel PA, Bliden KP, Butler K, Antonino MJ, Wei C, Teng R, Rasmussen L, Storey RF, Nielsen T, Eikelboom JW, Sabe-Affaki G, Husted S, Kereiakes DJ, Henderson D, Patel DV, Tantry US. Response to ticagrelor in clopidogrel nonresponders and responders and effect of switching therapies: the RESPOND study. Circulation, 2010; 121:1188-1199.

75. Wallentin L, Becker RC, Budaj A, Cannon CP, Emanuelsson H, Held C, Horrow J, Husted S, James S, Katus H, Mahaffey KW, Scirica BM, Skene A, Steg PG, Storey RF, Harrington RA. Ticagrelor versus clopidogrel in patients with acute coronary syndromes. N Engl J Med, 2009; 361:1045-1057.

76. Cannon CP, Harrington RA, James S, Ardissino D, Becker RC, Emanuelsson H, Husted S, Katus H, Keltai M, Khurmi NS, Kontny F, Lewis BS, Steg PG, Storey RF, Wojdyla D, Wallentin L. Comparison of ticagrelor with clopidogrel in patients with a planned invasive strategy for acute coronary syndromes (PLATO): a randomised double-blind study. Lancet, 2010; 375:283-293.

77. James S, Budaj A, Aylward P, Buck KK, Cannon $\mathrm{CP}$, Cornel JH, Harrington RA, Horrow J, Katus
H, Keltai M, Lewis BS, Parikh K, Storey RF, Szummer K, Wojdyla D, Wallentin L. Ticagrelor versus clopidogrel in acute coronary syndromes in relation to renal function: results from the Platelet Inhibition and Patient Outcomes (PLATO) trial. Circulation, 2010; 122:10561067.

78. Storey RF, Angiolillo DJ, Patil SB, Desai B, Ecob R, Husted S, Emanuelsson H, Cannon CP, Becker RC, Wallentin L. Inhibitory effects of ticagrelor compared with clopidogrel on platelet function in patients with acute coronary syndromes: the PLATO (PLATelet inhibition and patient Outcomes) PLATELET substudy. J Am Coll Cardiol, 2010; 56:1456-1462.

79. Steg PG, James S, Harrington RA, Ardissino D, Becker RC, Cannon CP, Emanuelsson H, Finkelstein A, Husted S, Katus H, Kilhamn J, Olofsson S, Storey RF, Weaver WD, Wallentin L. Ticagrelor versus clopidogrel in patients with ST-elevation acute coronary syndromes intended for reperfusion with primary percutaneous coronary intervention: A Platelet Inhibition and Patient Outcomes (PLATO) trial subgroup analysis. Circulation, 2010; 122:2131-2141.

80. Becker RC, Bassand JP, Budaj A, Wojdyla DM, James SK, Cornel JH, French J, Held C, Horrow J, Husted S, Lopez-Sendon J, Lassila R, Mahaffey KW, Storey RF, Harrington RA, Wallentin L. Bleeding complications with the P2Y12 receptor antagonists clopidogrel and ticagrelor in the PLATelet inhibition and patient Outcomes (PLATO) trial. Eur Heart J, 2011; 32:2933-2944.

81. Held C, Asenblad N, Bassand JP, Becker RC, Cannon CP, Claeys MJ, Harrington RA, Horrow J, Husted S, James SK, Mahaffey KW, Nicolau JC, Scirica BM,Storey RF, Vintila M, Ycas J, Wallentin L. Ticagrelor versus clopidogrel in patients with acute coronary syndromes undergoing coronary artery bypass surgery: results from the PLATO (Platelet Inhibition and Patient Outcomes) trial. J Am Coll Cardiol, 2011; 57:672-684.

82. James SK, Roe MT, Cannon CP, Cornel JH, Horrow J, Husted S, Katus H, Morais J, Steg PG, Storey RF, Stevens S, Wallentin L, Harrington RA. Ticagrelor versus clopidogrel in patients with acute coronary syndromes intended for noninvasive management: substudy from prospective randomised PLATelet inhibition and patient Outcomes (PLATO) trial. BMJ, 2011; 342:d3527.

83. Scirica BM, Cannon CP, Emanuelsson $\mathrm{H}$, Michelson EL, Harrington RA, Husted S, James S, Katus H, Pais P, Raev D, Spinar J, Steg PG, Storey RF, Wallentin L. The incidence of bradyarrhythmias and clinical bradyarrhythmic events in patients with acute coronary syndromes treated with ticagrelor or clopidogrel in the PLATO (Platelet Inhibition and Patient Outcomes) trial: results of the continuous electrocardiographic assessment 
substudy. J Am Coll Cardiol, 2011; 57:19081916.

84. Storey RF, Becker RC, Harrington RA, Husted S, James SK, Cools F, Steg PG, Khurmi NS, Emanuelsson H, Cooper A, Cairns $\mathrm{R}$, Cannon CP, Wallentin L. Characterization of dyspnoea in PLATO study patients treated with ticagrelor or clopidogrel and its association with clinical outcomes. Eur Heart J, 2011; 32:29452953.

85. Mandelzweig L, Battler A, Boyko V, Bueno H, Danchin N, Filippatos G, Gitt A, Hasdai D, Hasin Y, Marrugat J, Van de Werf F, Wallentin L, Behar S. The second Euro Heart Survey on acute coronary syndromes: Characteristics, treatment, and outcome of patients with ACS in Europe and the Mediterranean Basin in 2004. Eur Heart J, 2006; 27:2285-2293.

86. ACTIVE Writing Group of the ACTIVE Investigators, Connolly S, Pogue J, Hart R, Pfeffer M, Hohnloser S, Chrolavicius S, Pfeffer M, Hohnloser S, Yusuf S. Clopidogrel plus aspirin versus oral anticoagulation for atrial fibrillation in the Atrial fibrillation Clopidogrel Trial with Irbesartan for prevention of Vascular Events (ACTIVE W): a randomised controlled trial. Lancet, 2006; 367:1903-1912.

87. Patrono C. Prevention of myocardial infarction and stroke by aspirin: different mechanisms? Different dosage? Thromb Res, 1998; 92:S7-S12.

88. Nijjer SS, Davies JE, Francis DP. Quantitative comparison of clopidogrel $600 \mathrm{mg}$, prasugrel and ticagrelor, against clopidogrel 300 mg on major adverse cardiovascular events and bleeding in coronary stenting: synthesis of CURRENT-OASIS-7, TRITON-TIMI-38 and PLATO. Int J Cardiol, 2012; 158:181-185.

89. Brandt JT, Payne CD, Wiviott SD, Weerakkody G, Farid NA, Small DS, Jakubowski JA, Naganuma H, Winters KJ. A comparison of prasugrel and clopidogrel loading doses on platelet function: magnitude of platelet inhibition is related to active metabolite formation. Am Heart J, 2007; 153:66.e9-66.e16.

90. Jernberg T, Payne CD, Winters KJ, Darstein C, Brandt JT, Jakubowski JA, Naganuma H, Siegbahn A, Wallentin L. Prasugrel achieves greater inhibition of platelet aggregation and a lower rate of non-responders compared with clopidogrel in aspirin-treated patients with stable coronary artery disease. Eur Heart J, 2006; 27:1166-1173.

91. Bliden KP, Tantry US, Storey RF, Jeong YH, Gesheff M, Wei C, Gurbel PA. The effect of ticagrelor versus clopidogrel on high ontreatment platelet reactivity: combined analysis of the ONSET/OFFSET and RESPOND studies. Am Heart J, 2011; 162:160-165.

92. Storey RF, Bliden KP, Ecob R, Karunakaran A, Butler K, Wei C, Tantry U, Gurbel PA. Earlier recovery of platelet function after discontinuation of treatment with ticagrelor compared with clopidogrel in patients with high antiplatelet responses. J Thromb Haemost, 2011; 9:17301737.

93. Qureshi Z, Hobson AR. Clopidogrel "Resistance": Where are We Now? Cardiovasc Ther, 2011. In press. doi: 10.1111/j.17555922.2011.00296.x.

94. Gurbel PA, Bliden KP, Hiatt BL, O'Connor CM. Clopidogrel for coronary stenting: response variability, drug resistance, and the effect of pretreatment platelet reactivity. Circulation, 2003; 107:2908-2913.

95. Campo G, Valgimigli M, Gemmati D, Percoco G, Catozzi L, Frangione A, Federici F, Ferrari F, Tebaldi M, Luccarelli S, Parrinello G, Ferrari R. Poor responsiveness to clopidogrel: Drugspecific or class effect mechanism? Evidence from a clopidogrel-to-ticlopidine crossover study. J Am Coll Cardiol, 2007; 50:1132-1137.

96. Samara WM, Bliden KP, Tantry US, Gurbel PA. The difference between clopidogrel responsiveness and posttreatment platelet reactivity. Thromb Res, 2005; 115:89-94.

97. Anderson CD, Biffi A, Greenberg SM, Rosand J. Personalized approaches to clopidogrel therapy: are we there yet? Stroke, 2010; 41:2997-3002.

98. Simon T, Verstuyft C, Mary-Krause M, Quteineh L, Drouet E, Méneveau N, Steg PG, Ferrières J, Danchin N, Becquemont L. Genetic determinants of response to clopidogrel and cardiovascular events. N Engl J Med, 2009; 360:363-375.

99. Brandt JT, Close SL, Iturria SJ, Payne CD, Farid NA, Ernest CS 2nd, Lachno DR, Salazar D, Winters KJ. Common polymorphisms of CYP2C19 and CYP2C9 affect the pharmacokinetic and pharmacodynamic response to clopidogrel but not prasugrel. J Thromb Haemost, 2007; 5:2429-2436.

100. Varenhorst C, James S, Erlinge D, Brandt JT, Braun OO, Man M, Siegbahn A, Walker J, Wallentin L, Winters KJ, Close SL. Genetic variation of CYP2C19 affects both pharmacokinetic and pharmacodynamic responses to clopidogrel but not prasugrel in aspirin-treated patients with coronary artery disease. Eur Heart J, 2009; 30:1744-1752.

101. Park KW, Kim HS. Options to overcome clopidogrel response variability. Circ J, 2012; 76:287-292.

102. Holmes DR Jr, Dehmer GJ, Kaul S, Leifer D, O'Gara PT, Stein CM. ACCF/AHA clopidogrel clinical alert: approaches to the FDA "boxed warning": a report of the American College of Cardiology Foundation Task Force on clinical expert consensus documents and the American Heart Association endorsed by the Society for Cardiovascular Angiography and Interventions and the Society of Thoracic Surgeons. J Am Coll Cardiol, 2010; 56:321-341.

103. Angiolillo DJ, Ueno M. Optimizing platelet inhibition in clopidogrel poor metabolizers: therapeutic options and practical considerations. JACC Cardiovasc Interv, 2011; 4:411-414. 
104. Yin T, Miyata T. Pharmacogenomics of clopidogrel: evidence and perspectives. Thromb Res, 2011; 128:307-316.

105. Zabalza M, Subirana I, Sala J, Lluis-Ganella C, Lucas G, Tomás M, Masiá R, Marrugat J, Brugada R, Elosua R. Meta-analyses of the association between cytochrome CYP2C19 lossand gain-of-function polymorphisms and cardiovascular outcomes in patients with coronary artery disease treated with clopidogrel. Heart, 2012; 98:100-108.

106. Azmoon S, Angiolillo DJ. Switching antiplatelet regimens: alternatives to clopidogrel in patients with acute coronary syndrome undergoing PCI: A Review of the literature and practical considerations for the interventional cardiologist. Catheter Cardiovasc Interv, 2012. In press. doi: 10.1002/ccd.24480.

107. Hulot JS, Bura A, Villard E, Azizi M, Remones V, Goyenvalle C, Aiach M, Lechat P, Gaussem P. Cytochrome P450 2C19 loss-of-function polymorphism is a major determinant of clopidogrel responsiveness in healthy subjects. Blood, 2006; 108:2244-2247.

108. Minarik M, Kopeckova M, Gassman M, Osmancik P, Benesova L. Rapid testing of clopidogrel resistance by genotyping of CYP2C19 and CYP2C9 polymorphisms using denaturing on-chip capillary electrophoresis. Electrophoresis, 2012; 33:1306-1310.

109. Mega JL, Simon T, Collet JP, Anderson JL, Antman EM, Bliden K, Cannon CP, Danchin N, Giusti B, Gurbel P, Horne BD, Hulot JS, Kastrati A, Montalescot G, Neumann FJ, Shen L, Sibbing D, Steg PG, Trenk D, Wiviott SD, Sabatine MS. Reduced-function CYP2C19 genotype and risk of adverse clinical outcomes among patients treated with clopidogrel predominantly for PCI: a metaanalysis. JAMA, 20100; 304:1821-1830.

110. Bauer T, Bouman HJ, van Werkum JW, Ford NF, ten Berg JM, Taubert D. Impact of CYP2C19 variant genotypes on clinical efficacy of antiplatelet treatment with clopidogrel: systematic review and meta-analysis. BMJ, 2011; 343:d4588.

111. Suh JW, Koo BK, Zhang SY, Park KW, Cho JY, Jang IJ, Lee DS, Sohn DW, Lee MM, Kim HS. Increased risk of atherothrombotic events associated with cytochrome P450 3A5 polymorphism in patients taking clopidogrel. CMAJ, 2006; 174:1715-1722.

112. Gurbel PA, Bliden KP, Hayes KM, Yoho JA, Herzog WR, Tantry US. The relation of dosing to clopidogrel responsiveness and the incidence of high post-treatment platelet aggregation in patients undergoing coronary stenting. J Am Coll Cardiol, 2005; 45:1392-1396.

113. Collet JP, Hulot JS, Anzaha G, Pena A, Chastre T, Caron C, Silvain J, Cayla G, BellemainAppaix A, Vignalou JB, Galier S, Barthélémy O, Beygui F, Gallois V, Montalescot G. High doses of clopidogrel to overcome genetic resistance: the randomized crossover CLOVIS-2 (Clopidogrel and Response Variability Investigation Study 2). JACC Cardiovasc Interv, 2011; 4:392-402.

114. Bouman HJ, Schömig E, van Werkum JW, Velder J, Hackeng CM, Hirschhäuser C, Waldmann C, Schmalz HG, ten Berg JM, Taubert D. Paraoxonase-1 is a major determinant of clopidogrel efficacy. Nat Med, 2011; 17:110116.

115. Edwards IR, Aronson JK. Adverse drug reactions: definitions, diagnosis, and management. Lancet, 2000; 356:1255-1259.

116. Neuman M, Nicar M. Apoptosis in ibuprofeninduced Stevens-Johnson syndrome. Transl Res, 2007; 149:254-259.

117. Lokhandwala J, Best PJ, Henry Y, Berger PB. Allergic reactions to clopidogrel and crossreactivity to other agents. Curr Allergy Asthma Rep, 2011; 11:52-57.

118. Cheema AN, Mohammad A, Hong T, Jakubovic HR, Parmar GS, Sharieff W, Garvey MB, Kutryk MJ, Fam NP, Graham JJ, Chisholm RJ. Characterization of clopidogrel hypersensitivity reactions and management with oral steroids without clopidogrel discontinuation. J Am Coll Cardiol, 2011; 58:1445-1454.

119. Meadows TA, Bhatt DL. Clinical aspects of platelet inhibitors and thrombus formation. Circ Res, 2007; 100:1261-1275.

120. Alli O, Smith C, Hoffman M, Amanullah S, Katz $\mathrm{P}$, Amanullah AM. Incidence, predictors, and outcomes of gastrointestinal bleeding in patients on dual antiplatelet therapy with aspirin and clopidogrel. J Clin Gastroenterol, 2011; 45:410414.

121. Kalyanasundaram A, Lincoff AM. Managing adverse effects and drug-drug interactions of antiplatelet agents. Nat Rev Cardiol, 2011; 8:592600.

122. Bennett CL, Connors JM, Carwile JM, Moake JL, Bell WR, Tarantolo SR, McCarthy LJ, Sarode R, Hatfield AJ, Feldman MD, Davidson CJ, Tsai HM. Thrombotic thrombocytopenic purpura associated with clopidogrel. N Engl J Med, 2000; 342:1773-1777.

123. Lokhandwala JO, Best PJ, Butterfield JH, Skelding KA, Scott T, Blankenship JC, Buckley $\mathrm{JW}$, Berger PB. Frequency of allergic or hematologic adverse reactions to ticlopidine among patients with allergic or hematologic adverse reactions to clopidogrel. Circ Cardiovasc Interv, 2009; 2:348-351.

124. European Medicine Agency. Interaction between clopidogrel and proton-pump inhibitors. 2010. Last accessed Sept $19 \quad 2012$. http://www.emea.europa.eu/docs/en_GB/docume nt_library/Public_statement/2010/03/WC500076 346.pdf.

125. Hochholzer W, Wiviott SD, Antman EM, Contant CF, Guo J, Giugliano RP, Dalby AJ, Montalescot G, Braunwald E. Predictors of bleeding and time dependence of association of bleeding with mortality: insights from the Trial to Assess Improvement in Therapeutic Outcomes by 
Optimizing Platelet Inhibition With Prasugrel-Thrombolysis in Myocardial Infarction 38 (TRITON-TIMI 38). Circulation, 2011; 123:2681-2689.

126. Ruff CT, Giugliano RP, Antman EM, Murphy SA, Lotan C, Heuer H, Merkely B, Baracioli L, Schersten F, Seabro-Gomes R, Braunwald E, Wiviott SD. Safety and efficacy of prasugrel compared with clopidogrel in different regions of the world. Int J Cardiol, 2012; 155:424-429.

127. Wiviott SD, Desai N, Murphy SA, Musumeci G, Ragosta M, Antman EM, Braunwald E. Efficacy and safety of intensive antiplatelet therapy with prasugrel from TRITON-TIMI 38 in a core clinical cohort defined by worldwide regulatory agencies. Am J Cardiol, 2011; 108:905-911.

128. James S, Akerblom A, Cannon CP, Emanuelsson H, Husted S, Katus H, Skene A, Steg PG, Storey $\mathrm{RF}$, Harrington $\mathrm{R}$, Becker $\mathrm{R}$, Wallentin L. Comparison of ticagrelor, the first reversible oral $\mathrm{P} 2 \mathrm{Y}(12)$ receptor antagonist, with clopidogrel in patients with acute coronary syndromes: Rationale, design, and baseline characteristics of the PLATelet inhibition and patient Outcomes (PLATO) trial. Am Heart J, 2009; 157:599-605.

129. Maseneni S, Donzelli M, Taegtmeyer AB, Brecht K, Krähenbühl S. Toxicity of clopidogrel and ticlopidine on human myeloid progenitor cells: importance of metabolites. Toxicology, 2012; 299:139-145.

130. Angiolillo DJ, Capranzano P, Ferreiro JL, Ueno M, Capodanno D, Dharmashankar K, Darlington A, Sumner S, Desai B, Charlton RK, Box LC, Zenni M, Guzman LA, Bass TA. Impact of adjunctive cilostazol therapy on platelet function profiles in patients with and without diabetes mellitus on aspirin and clopidogrel therapy. Thromb Haemost, 2011; 106:253-262.

131. Neuman MG, Cohen L, Nanau RM, Hwang PA. Genetic and immune predictors for hypersensitivity syndrome to antiepileptic drugs. Transl Res, 2012; 159:397-406.

132. Campbell KL, Cohn JR, Fischman DL, Walinsky P, Mallya R, Jaffrani W, Savage MP. Management of clopidogrel hypersensitivity without drug interruption. Am J Cardiol, 2011; 107:812-816.

133. Makkar K, Wilensky RL, Julien MB, Herrmann HC, Spinler SA. Rash with both clopidogrel and ticlopidine in two patients following percutaneous coronary intervention with drugeluting stents. Ann Pharmacother, 2006; 40:12041207.

134. Rajan TV. The Gell-Coombs classification of hypersensitivity reactions: a re-interpretation. Trends Immunol, 2003; 24:376-379.

135. Camara MG, Almeda FQ. Clopidogrel (Plavix) desensitization: a case series. Catheter Cardiovasc Interv, 2005; 65:525-527.

136. McKenzie DB, Rao U, Hobson A, Levy T, Talwar S, Swallow R. A novel strategy for managing clopidogrel-induced adverse skin reactions. EuroIntervention, 2009; 5:470-474.

137. Nakamizo S, Kobayashi S, Usui T, Miyachi Y, Kabashima K. Clopidogrel-induced acute generalized exanthematous pustulosis with elevated Th17 cytokine levels as determined by a drug lymphocyte stimulation test. Br J Dermatol, 2010; 162:1402-1403.

138. Fajt M, Petrov A. Clopidogrel hypersensitivity: a novel multi-day outpatient oral desensitization regimen. Ann Pharmacother, 2010; 44:11-8.

139. Lee-Wong M, Gadhvi D, Resnick D. Clopidogrel desensitization. Ann Allergy Asthma Immunol, 2006; 96:756-757.

140. El-Majjaoui S, Tournillac I, Pinzani V, Dandurand M, Guillot B. Toxic skin reaction to clopidogrel. J Mal Vasc, 2001; 26:207-208.

141. Sarrot-Reynauld F, Bouillet L, Bourrain JL. Severe hypersensitivity associated with clopidogrel. Ann Intern Med, 2001; 135:305-306.

142. Comert A, Akgun S, Civelek A, Kavala M, Sarigül S, Yildirim T, Arsan S. Clopidogrelinduced hypersensitivity syndrome associated with febrile pancytopenia. Int J Dermatol, 2005; 44:882-884.

143. Gutiérrez-Fernández D, Fuentes-Vallejo MS, Rueda-Ygueravides MD, Foncubierta-Fernández A, León-Jiménez A. Immediate hypersensitivity and delayed hypersensitivity to clopidogrel. Allergol Immunopathol (Madr), 2007; 35:213215.

144. Oppedijk B, Odekerken DA, van der Wildt JJ, Melissant CF. Rapid oral desensitisation procedure in clopidogrel hypersensitivity. Neth Heart J, 2008; 16:21-23.

145. Chopra P, Verma P, Klaustermeyer WB. Successful use of prasugrel, an alternative antiplatelet agent, in a patient with clopidogrel allergy. Ann Allergy Asthma Immunol, 2011; 107:541-542.

146. Owen P, Garner J, Hergott L, Page RL 2nd. Clopidogrel desensitization: case report and review of published protocols. Pharmacotherapy, 2008; 28:259-270.

147. Gowda RM, Misra D, Khan IA. Hypersensitivity skin rash: an adverse drug reaction to clopidogrel loading dose. Int J Cardiol, 2004; 95:333.

148. Khambekar SK, Kovac J, Gershlick AH. Clopidogrel induced urticarial rash in a patient with left main stem percutaneous coronary intervention: management issues. Heart, 2004; 90:e14.

149. Satish B, Tressa K, Harish CR. Case report on clopidogrel rash after coronary placement of a paclitaxol-coated stent. Crit Pathw Cardiol, 2007; 6:24-25.

150. Fernando SL, Assaad NN. Rapid and sequential desensitization to both aspirin and clopidogrel. Intern Med J, 2010; 40:596-599.

151. Doogue MP, Begg EJ, Bridgman P. Clopidogrel hypersensitivity syndrome with rash, fever, and neutropenia. Mayo Clin Proc, 2005; 80:13681370. 
152. van Werkum JW, Braber TL, Verheggen PW, Van Der Have-Roeffel SM. Prasugrel as alternative treatment strategy in a case with a hypersensitivity reaction to clopidogrel. Platelets, $2011 ; 22: 75-76$.

153. Mutnick JL. Desensitization to prasugrel: cardiology's increased need for allergy consultation. Ann Allergy Asthma Immunol, 2012; 108:124-125.

154. Deshmukh AJ, Pant S, Cook J, Sachdeva R, Rutlen D, Uretsky BF. Prasugrel-induced rash. Ann Pharmacother, 2012; 46:1123-1125.

155. Raccah BH, Shalit M, Danenberg HD. Allergic reaction to prasugrel and cross-reactivity with clopidogrel. Int J Cardiol, 2012; 157:e48-e49.

156. Fernández-Ruiz M, Carbonell-Porras A, GarcíaReyne A, López-Medrano F. Management of a Hypersensitivity Reaction to Thienopyridines: Prasugrel-Induced Fever and Hepatitis Resolved After Switching to Clopidogrel. Rev Esp Cardiol, 2012; 65:773-774.

157. Kushner FG, Hand M, Smith SC Jr, King SB 3rd, Anderson JL, Antman EM, Bailey SR, Bates ER, Blankenship JC, Casey DE Jr, Green LA, Hochman JS, Jacobs AK, Krumholz HM, Morrison DA, Ornato JP, Pearle DL, Peterson ED, Sloan MA, Whitlow PL, Williams DO. 2009 Focused Updates: ACC/AHA Guidelines for the Management of Patients With ST-Elevation Myocardial Infarction (updating the 2004 Guideline and 2007 Focused Update) and ACC/AHA/SCAI Guidelines on Percutaneous Coronary Intervention (updating the 2005 Guideline and 2007 Focused Update): a report of the American College of Cardiology Foundation/American Heart Association Task Force on Practice Guidelines. Circulation, 2009; 120:2271-2306.

158. Peppard SR, Held-Godgluck BM, Beddingfield $\mathrm{R}$. Use of prasugrel in a patient with clopidogrel hypersensitivity. Ann Pharmacother, 2011; 45:e54.

159. Jeung YJ, Lee JY, Oh MJ, Choi DC, Lee BJ. Comparison of the causes and clinical features of drug rash with eosinophilia and systemic symptoms and stevens-johnson syndrome. Allergy Asthma Immunol Res, 2010; 2:123-126.

160. Hou XM, Wu WY. Toxic epidermal necrolysis after percutaneous coronary intervention: which drug is the culprit? Chin Med J (Engl), 2011; 124:467-468.

161. Gurbel PA, Jeong YH, Tantry US. Cutaneous clopidogrel hypersensitivity: give steroids and do not stop the clopidogrel. J Am Coll Cardiol, 2011; 58:1455-1456.

162. Iakovou I, Schmidt $\mathrm{T}$, Bonizzoni $\mathrm{E}$, Ge L, Sangiorgi GM, Stankovic G, Airoldi F, Chieffo A, Montorfano M, Carlino M, Michev I, Corvaja $\mathrm{N}$, Briguori C, Gerckens U, Grube E, Colombo A. Incidence, predictors, and outcome of thrombosis after successful implantation of drugeluting stents. JAMA, 2005; 293:2126-2130.
163. Conforti A, Costantini D, Zanetti F, Moretti U, Grezzana M, Leone R. Adverse drug reactions in older patients: an Italian observational prospective hospital study. Drug Healthc Patient Saf, 2012; 4:75-80.

164. Nguyen JK, Fouts MM, Kotabe SE, Lo E. Polypharmacy as a risk factor for adverse drug reactions in geriatric nursing home residents. Am J Geriatr Pharmacother, 2006; 4:36-41.

165. Walker NE, Fasano MB, Hobbs RA, Horwitz PA. Clopidogrel desensitization protocol for the treatment of thienopyridine hypersensitivity. Crit Pathw Cardiol, 2007; 6:26-29.

166. von Tiehl KF, Price MJ, Valencia R, Ludington KJ, Teirstein PS, Simon RA. Clopidogrel desensitization after drug-eluting stent placement. J Am Coll Cardiol, 2007; 50:2039-2043.

167. Neuman MG, Malkiewicz IM, Shear NH. A novel lymphocyte toxicity assay to assess drug hypersensitivity syndromes. Clin Biochem, 2000; 33:517-524.

168. Shear NH, Spielberg SP. Anticonvulsant hypersensitivity syndrome. In vitro assessment of risk. J Clin Invest, 1988; 82:1826-1832.

169. Neuman MG, Shear NH, Malkiewicz IM, Taeri M, Shapiro LE, Krivoy N, Haber J, Gomez M, Fish J, Cartotto R, Cohen L. Immunopathogenesis of hypersensitivity syndrome reactions to sulfonamides. Transl Res, 2007; 149:243-253.

170. Neuman MG, Shear NH, Malkiewicz IM, Kessas M, Lee AW, Cohen L. Predicting possible zonisamide hypersensitivity syndrome. Exp Dermatol, 2008; 17:1045-1051.

171. Neuman MG, Malkiewicz IM, Phillips EJ, Rachlis AR, Ong D, Yeung E, Shear NH. Monitoring adverse drug reactions to sulfonamide antibiotics in human immunodeficiency virus-infected individuals. Ther Drug Monit, 2002; 24:728-736.

172. Ng JA, Goldberg N, Tafreshi MJ. Clopidogrelinduced hepatotoxicity and fever. Pharmacotherapy, 2006; 26:1023-1026.

173. Goyal RK, Srivastava D, Lessnau KD. Clopidogrel-induced hepatocellular injury and cholestatic jaundice in an elderly patient: case report and review of the literature. Pharmacotherapy, 2009; 29:608-612.

174. Skurnik YD, Tcherniak A, Edlan K, Sthoeger Z. Ticlopidine-induced cholestatic hepatitis. Ann Pharmacother, 2003; 37:371-375.

175. Tholl U, Anlauf M, Helmchen U. Clopidogrel and membranous nephropathy. Lancet, 1999; 354:1443-1444.

176. Ghosh S, Bandyopadhyay D. Haemorrhagic herpes zoster associated with clopidogrel treatment. Clin Exp Dermatol, 2009; 34:409-410.

177. Bhatt DL, Scheiman J, Abraham NS, Antman EM, Chan FK, Furberg CD, Johnson DA, Mahaffey KW, Quigley EM; American College of Cardiology Foundation Task Force on Clinical Expert Consensus Documents. ACCF/ACG/AHA 2008 expert consensus document on reducing the 
gastrointestinal risks of antiplatelet therapy and NSAID use: a report of the American College of Cardiology Foundation Task Force on Clinical Expert Consensus Documents. Circulation, 2008; 118:1894-1909.

178. Mackenzie IS, Coughtrie MW, MacDonald TM, Wei L. Antiplatelet drug interactions. J Intern Med, 2010; 268:516-529.

179. Macaione F, Montaina C, Evola S, Novo G, Novo S. Impact of dual antiplatelet therapy with proton pump inhibitors on the outcome of patients with acute coronary syndrome undergoing drug-eluting stent implantation. ISRN Cardiol, 2012; 2012:692761.

180. Kwok CS, Loke YK. Meta-analysis: the effects of proton pump inhibitors on cardiovascular events and mortality in patients receiving clopidogrel. Aliment Pharmacol Ther, 2010; 31:810-823.

181. Juurlink DN, Gomes T, Ko DT, Szmitko PE, Austin PC, Tu JV, Henry DA, Kopp A, Mamdani MM. A population-based study of the drug interaction between proton pump inhibitors and clopidogrel. CMAJ, 2009; 180:713-718

182. O'Donoghue ML, Braunwald E, Antman EM, Mu rphy SA, Bates ER, Rozenman Y, Michelson AD, Hautvast RW, Ver Lee PN, Close SL, Shen L, Mega JL,Sabatine MS, Wiviott SD. Pharmacodynamic effect and clinical efficacy of clopidogrel and prasugrel with or without a proton-pump inhibitor: an analysis of two randomised trials. Lancet, 2009; 374:989-997.

183. Angiolillo DJ, Gibson CM, Cheng S, Ollier C, Nicolas O, Bergougnan L, Perrin L, LaCreta FP, Hurbin F, Dubar M. Differential effects of omeprazole and pantoprazole on the pharmacodynamics and pharmacokinetics of clopidogrel in healthy subjects: randomized, placebo-controlled, crossover comparison studies. Clin Pharmacol Ther, 2011; 89:65-74.

184. Bates ER, Lau WC, Angiolillo DJ. Clopidogreldrug interactions. J Am Coll Cardiol, 2011; 57:1251-1263.

185. Rassen JA, Choudhry NK, Avorn J, Schneeweiss $\mathrm{S}$. Cardiovascular outcomes and mortality in patients using clopidogrel with proton pump inhibitors after percutaneous coronary intervention or acute coronary syndrome. Circulation, 2009; 120:2322-2329.

186. Rossini R, Capodanno D, Musumeci G, Lettieri C, Lortkipanidze N, Romano M, Nijaradze T, Tarantini G, Cicorella N, Sirbu V, Guagliumi G, Rosiello R, Valsecchi O, Gavazzi A. Safety of clopidogrel and proton pump inhibitors in patients undergoing drug-eluting stent implantation. Coron Artery Dis, 2011; 22:199205.

187. Ray WA, Murray KT, Griffin MR, Chung $\mathrm{CP}$, Smalley WE, Hall K, Daugherty JR, Kaltenbach LA, Stein CM. Outcomes with concurrent use of clopidogrel and proton-pump inhibitors: a cohort study. Ann Intern Med, 2010; 152:337-345.

188. Harrison RW, Mahaffey KW. Clopidogrel and PPI interaction: clinically relevant or not? Curr Cardiol Rep, 2012; 14:49-58.

189. Charlot M, Ahlehoff O, Norgaard ML, Jørgensen CH, Sørensen R, Abildstrøm SZ, Hansen PR, Madsen JK, Køber L, Torp-Pedersen C, Gislason G. Proton-pump inhibitors are associated with increased cardiovascular risk independent of clopidogrel use: a nationwide cohort study. Ann Intern Med, 2010; 153:378-386.

190. Nair PK, Mulukutla SR, Marroquin OC. Stents and statins: history, clinical outcomes and mechanisms. Expert Rev Cardiovasc Ther, 2010; 8:1283-1295.

191. Schmidt M, Johansen MB, Maeng M, Kaltoft A, Jensen LO, Tilsted HH, Bøtker HE, Baron JA, Sørensen HT. Concomitant use of clopidogrel and statins and risk of major adverse cardiovascular events following coronary stent implantation. Br J Clin Pharmacol, 2012; 74:161170.

192. Clarke TA, Waskell LA. The metabolism of clopidogrel is catalyzed by human cytochrome P450 3A and is inhibited by atorvastatin. Drug Metab Dispos, 2003; 31:53-59.

193. Lau WC, Waskell LA, Watkins PB, Neer CJ, Horowitz K, Hopp AS, Tait AR, Carville DG, Guyer KE, Bates ER. Atorvastatin reduces the ability of clopidogrel to inhibit platelet aggregation: a new drug-drug interaction. Circulation, 2003; 107:32-37.

194. Neubauer H, Günesdogan B, Hanefeld C, Spiecker M, Mügge A. Lipophilic statins interfere with the inhibitory effects of clopidogrel on platelet function--a flow cytometry study. Eur Heart J, 2003; 24:1744-1749.

195. Mach F, Senouf D, Fontana P, Boehlen F, Reber G, Daali Y, de Moerloose P, Sigwart U. Not all statins interfere with clopidogrel during antiplatelet therapy. Eur J Clin Invest, 2005; 35:476-481.

196. Smith SM, Judge HM, Peters G, Storey RF. Multiple antiplatelet effects of clopidogrel are not modulated by statin type in patients undergoing percutaneous coronary intervention. Platelets, 2004; 15:465-474.

197. Good CW, Steinhubl SR, Brennan DM, Lincoff AM, Topol EJ, Berger PB. Is there a clinically significant interaction between calcium channel antagonists and clopidogrel?: results from the Clopidogrel for the Reduction of Events During Observation (CREDO) trial. Circ Cardiovasc Interv, 2012; 5:77-81.

198. Siller-Matula JM, Lang I, Christ G, Jilma B. Calcium-channel blockers reduce the antiplatelet effect of clopidogrel. J Am Coll Cardiol, 2008; 52:1557-1563.

199. Gremmel T, Steiner S, Seidinger D, Koppensteiner R, Panzer S, Kopp CW. Calciumchannel blockers decrease clopidogrel-mediated platelet inhibition. Heart, 2010; 96:186-189. 
200. Schmidt M, Johansen MB, Robertson DJ, Maeng M, Kaltoft A, Jensen LO, Tilsted HH, Bøtker HE, Sørensen HT, Baron JA. Use of clopidogrel and calcium channel blockers and risk of major adverse cardiovascular events. Eur J Clin Invest, 2012; 42:266-274.

201. Srinivasan M, Smith D. Drug interaction with anti-mycobacterial treatment as a cause of clopidogrel resistance. Postgrad Med J, 2008; 84:217-219.

202. Sabin CA, Worm SW, Weber R, Reiss P, El-Sadr W, Dabis F, De Wit S, Law M, D'Arminio Monforte A, Friis-Møller N, Kirk O, Pradier C, Weller I, Phillips AN, Lundgren JD. Use of nucleoside reverse transcriptase inhibitors and risk of myocardial infarction in HIV-infected patients enrolled in the D:A:D study: a multicohort collaboration. Lancet, 2008; 371:14171426.

203. Daali Y, Ancrenaz V, Bosilkovska M, Dayer P, Desmeules J. Ritonavir inhibits the two main prasugrel bioactivation pathways in vitro: a potential drug-drug interaction in HIV patients. Metabolism, 2011; 60:1584-1589.

204. Lesko LJ, Schmidt S. Individualization of drug therapy: history, present state, and opportunities for the future. Clin Pharmacol Ther, 2012; 92:458-466.

205. Reynolds KS. Achieving the promise of personalized medicine. Clin Pharmacol Ther, 2012; 92:401-405.

206. Weber AA, Adamzik M, Bachmann HS, Görlinger $\mathrm{K}$, Grandoch $\mathrm{M}$, Leineweber $\mathrm{K}$, Müller-Beissenhirtz H, Wenzel F, Naber C; Interdisciplinary Study Group - Clinical Pharmacology of Haemostasis. Methods to evaluate the pharmacology of oral antiplatelet drugs. Herz, 2008; 33:287-296.

207. Seidel H, Rahman MM, Scharf RE. Monitoring of antiplatelet therapy. Current limitations, challenges, and perspectives. Hamostaseologie, 2011; 31:41-51.

208. Nirogi RV, Kandikere VN, Shukla M, Mudigonda K, Maurya S, Boosi R. Quantification of clopidogrel in human plasma by sensitive liquid chromatography/tandem mass spectrometry. Rapid Commun Mass Spectrom, 2006; 20:1695-1700.

209. Shin BS, Yoo SD. Determination of clopidogrel in human plasma by liquid chromatography/tandem mass spectrometry: application to a clinical pharmacokinetic study. Biomed Chromatogr, 2007; 21:883-889.

210. Farid NA, McIntosh M, Garofolo F, Wong E, Shwajch A, Kennedy M, Young M, Sarkar P, Kawabata K, Takahashi M, Pang H. Determination of the active and inactive metabolites of prasugrel in human plasma by liquid chromatography/tandem mass spectrometry. Rapid Commun Mass Spectrom, 2007; 21:169-179.

211. Sillén H, Cook M, Davis P. Determination of ticagrelor and two metabolites in plasma samples by liquid chromatography and mass spectrometry. J Chromatogr B Analyt Technol Biomed Life Sci, 2010; 878:2299-2306.

212. Teng R, Butler K. Pharmacokinetics, pharmacodynamics, tolerability and safety of single ascending doses of ticagrelor, a reversibly binding oral P2Y(12) receptor antagonist, in healthy subjects. Eur J Clin Pharmacol, 2010; 66:487-496.

213. Lev EI, Patel RT, Maresh KJ, Guthikonda S, Granada J, DeLao T, Bray PF, Kleiman NS. Aspirin and clopidogrel drug response in patients undergoing percutaneous coronary intervention: the role of dual drug resistance. J Am Coll Cardiol, 2006; 47:27-33.

214. Bonello L, Camoin-Jau L, Arques S, Boyer C, Panagides D, Wittenberg O, Simeoni MC, Barragan P, Dignat-George F, Paganelli F. Adjusted clopidogrel loading doses according to vasodilator-stimulated phosphoprotein phosphorylation index decrease rate of major adverse cardiovascular events in patients with clopidogrel resistance: a multicenter randomized prospective study. J Am Coll Cardiol, 2008; 51:1404-1411.

215. Craft RM, Chavez JJ, Bresee SJ, Wortham DC, Cohen E, Carroll RC. A novel modification of the Thrombelastograph assay, isolating platelet function, correlates with optical platelet aggregation. J Lab Clin Med, 2004; 143:301-309.

216. Bernlochner I, Sibbing D. Thienopyridines and Other ADP-Receptor Antagonists. Handb Exp Pharmacol, 2012; 210:165-198.

217. Rodríguez-Monguió R, Otero MJ, Rovira J. Assessing the economic impact of adverse drug effects. Pharmacoeconomics, 2003; 21:623-650. 


\begin{tabular}{|c|c|c|c|c|}
\hline Clinical Trial (Ref. \#) & $\begin{array}{l}\text { Population } \\
\text { Characteristics }\end{array}$ & Medication Compared & Medication Doses & Risk Factors and Medical History \\
\hline CAPRIE (42) & $\begin{array}{l}19185 \text { patients with } \\
\text { atherosclerotic CV } \\
\text { disease manifested as } \\
\text { either recent ischemic } \\
\text { stroke, recent MI or } \\
\text { symptomatic peripheral } \\
\text { arterial disease } \\
\text { Mean age } 62.5\end{array}$ & Clopidogrel vs. aspirin & $\begin{array}{l}\text { Clopidogrel } \\
\text { ( } 75 \mathrm{mg} / \text { day) } \\
\text { Aspirin (325 mg/day) }\end{array}$ & $\begin{array}{l}\text { History of ischemic stroke } \\
\text { Transient ischemic attack/reversible ischemic } \\
\text { neurological deficit } \\
\text { Diabetes mellitus } \\
\text { Hypertension } \\
\text { Hypercholesterolemia } \\
\text { Angina } \\
\text { MI } \\
\text { Congestive heart failure } \\
\text { Cardiomegaly } \\
\text { Atrial fibrillation } \\
\text { Intermittent claudication } \\
\text { Past or current smoking }\end{array}$ \\
\hline CURE $(43,44)$ & $\begin{array}{l}6259 \text { patients receiving } \\
\text { clopidogrel plus aspirin } \\
6303 \text { patients receiving } \\
\text { placebo plus aspirin } \\
\text { Mean age } 62.2\end{array}$ & $\begin{array}{l}\text { Clopidogrel plus } \\
\text { aspirin vs. placebo plus } \\
\text { aspirin }\end{array}$ & $\begin{array}{l}\text { Clopidogrel ( } 300 \mathrm{mg} \mathrm{LD}, 75 \mathrm{mg} \\
\text { MD) plus aspirin }(75-325 \mathrm{mg}) \\
\text { Placebo plus aspirin }(75-325 \mathrm{mg})\end{array}$ & $\begin{array}{l}\text { History of MI } \\
\text { History of CABG/ percutaneous transluminal } \\
\text { coronary angioplasty } \\
\text { Stroke } \\
\text { Heart failure } \\
\text { Hypertension } \\
\text { Diabetes } \\
\text { Past or current smoking } \\
\text { Aspirin } \\
\text { Heparin } \\
\text { Angiotensin-converting enzyme inhibitors } \\
\beta \text {-blockers } \\
\text { Calcium channel blockers } \\
\text { Lipid-lowering agents } \\
\text { Intravenous nitrate }\end{array}$ \\
\hline PCI-CURE (45) & $\begin{array}{l}1313 \text { patients with non- } \\
\text { ST segment elevation } \\
\text { ACS undergoing PCI } \\
\text { receiving clopidogrel } \\
\text { plus aspirin } \\
1345 \text { patients receiving } \\
\text { placebo plus aspirin } \\
\text { Mead age } 61.5\end{array}$ & $\begin{array}{l}\text { Clopidogrel plus } \\
\text { aspirin vs. placebo plus } \\
\text { aspirin }\end{array}$ & $\begin{array}{l}\text { Clopidogrel (300 mg LD, } 75 \mathrm{mg} \\
\text { MD) plus aspirin }(75-325 \mathrm{mg}) \\
\text { Placebo plus aspirin }(75-325 \mathrm{mg})\end{array}$ & $\begin{array}{l}\text { Diabetes } \\
\text { Previous MI } \\
\text { Previous PCI } \\
\text { Previous CABG } \\
\text { Smoking }\end{array}$ \\
\hline
\end{tabular}




\begin{tabular}{|c|c|c|c|c|}
\hline CREDO (45) & $\begin{array}{l}2116 \text { patients } \\
\text { undergoing elective } \\
\text { PCI } \\
\text { Mean age } 61.6\end{array}$ & $\begin{array}{l}\text { Clopidogrel plus } \\
\text { aspirin vs. placebo plus } \\
\text { aspirin }\end{array}$ & $\begin{array}{l}\text { Clopidogrel (300 mg LD, } 75 \mathrm{mg} \\
\text { MD) plus aspirin }(75 \mathrm{mg}) \\
\text { Placebo plus aspirin }(75 \mathrm{mg})\end{array}$ & $\begin{array}{l}\text { History of MI } \\
\text { Stroke } \\
\text { Peripheral vascular disease } \\
\text { Diabetes } \\
\text { Hypertension } \\
\text { Hyperlipidemia } \\
\text { Family history of CV disease } \\
\text { Past or current smoker } \\
\text { Aspirin } \\
\beta \text {-blockers } \\
\text { Statins } \\
\text { Angiotensin-converting enzyme inhibitors } \\
\text { Calcium channel blockers }\end{array}$ \\
\hline CARESS (47) & $\begin{array}{l}107 \text { patients with } \\
\text { asymptomatic } \\
\text { microembolic signals } \\
\text { (indicator of future } \\
\text { stroke and transient } \\
\text { ischemic attack) at } \\
\text { baseline } \\
\text { Mean age } 64.5\end{array}$ & $\begin{array}{l}\text { Clopidogrel plus } \\
\text { aspirin vs. placebo plus } \\
\text { aspirin }\end{array}$ & $\begin{array}{l}\text { Clopidogrel (300 mg LD, } 75 \mathrm{mg} \\
\text { MD) plus aspirin }(75 \mathrm{mg}) \\
\text { Placebo plus aspirin }(75 \mathrm{mg})\end{array}$ & $\begin{array}{l}\text { History of stroke Hypertension } \\
\text { Diabetes } \\
\text { Hypercholesterolemia } \\
\text { Prior MI } \\
\text { Prior coronary bypass } \\
\text { Prior coronary stenting/angioplasty } \\
\text { Peripheral artery disease } \\
\text { Statin therapy } \\
\text { Drugs acting on the renin-angiotensin system } \\
\beta \text {-blocking agents } \\
\text { Calcium channel blockers } \\
\text { Peroxisome proliferator-activated receptor- } \gamma \text { agonists }\end{array}$ \\
\hline CLARITY-TIMI 28 (48) & $\begin{array}{l}3491 \text { patients with } \\
\text { STEMI } \\
\text { Mean age } 57.5\end{array}$ & $\begin{array}{l}\text { Clopidogrel plus } \\
\text { aspirin vs. placebo plus } \\
\text { aspirin }\end{array}$ & $\begin{array}{l}\text { Clopidogrel (300 mg LD, } 75 \mathrm{mg} \\
\text { MD) plus aspirin }(75-162 \mathrm{mg}) \\
\text { Placebo plus aspirin }(75-162 \mathrm{mg})\end{array}$ & $\begin{array}{l}\text { Hypertension } \\
\text { Fibrinolytic agents } \\
\text { Aspirin } \\
\text { Heparin (dispensed } \\
\text { according to body weight) } \\
\text { Prior lipid-lowering agents }\end{array}$ \\
\hline PCI-CLARITY (49) & $\begin{array}{l}1863 \text { patients } \\
\text { undergoing PCI after } \\
\text { mandated angiography } \\
\text { Mean age } 57.3\end{array}$ & $\begin{array}{l}\text { Clopidogrel plus } \\
\text { aspirin vs. placebo plus } \\
\text { aspirin }\end{array}$ & $\begin{array}{l}\text { Clopidogrel (300 mg LD, } 75 \mathrm{mg} \\
\text { MD) plus aspirin }(75-162 \mathrm{mg}) \\
\text { Placebo plus aspirin }(75-162 \mathrm{mg})\end{array}$ & $\begin{array}{l}\text { Hypertension } \\
\text { Hyperlipidemia } \\
\text { Current smoker } \\
\text { Diabetes mellitus } \\
\text { Prior MI } \\
\text { Prior PCI } \\
\text { Fibrinolytic agents and heparin }\end{array}$ \\
\hline
\end{tabular}




\begin{tabular}{|c|c|c|c|c|}
\hline ECG CLARITY-TIMI 28 (50) & $\begin{array}{l}2431 \text { patients with } \\
\text { STEMI with available } \\
\text { electrocardiogram } \\
\text { Mean age } 57.5\end{array}$ & $\begin{array}{l}\text { Clopidogrel plus } \\
\text { aspirin vs. placebo plus } \\
\text { aspirin }\end{array}$ & $\begin{array}{l}\text { Clopidogrel (300 mg LD, } 75 \mathrm{mg} \\
\text { MD) plus aspirin }(75-162 \mathrm{mg}) \\
\text { Placebo plus aspirin }(75-162 \mathrm{mg})\end{array}$ & $\begin{array}{l}\text { Hypertension } \\
\text { Diabetes } \\
\text { Prior aspirin } \\
\text { Prior lipid-lowering agents }\end{array}$ \\
\hline COMMIT (51) & $\begin{array}{l}45852 \text { patients with } \\
\text { acute MI } \\
\text { Mean age } 61.3\end{array}$ & $\begin{array}{l}\text { Clopidogrel plus } \\
\text { aspirin vs. placebo plus } \\
\text { aspirin }\end{array}$ & $\begin{array}{l}\text { Clopidogrel } \\
\text { (75 mg) plus aspirin }(162 \mathrm{mg}) \\
\text { Placebo plus aspirin }(162 \mathrm{mg})\end{array}$ & $\begin{array}{l}\text { Prior MI } \\
\text { Hypertension } \\
\text { Aspirin } \\
\text { Fibrinolytic agents } \\
\beta \text {-blocking agents } \\
\text { Anticoagulants } \\
\text { Antiarrhythmic agents } \\
\text { Angiotensin-converting enzyme inhibitors } \\
\text { Nitrate } \\
\text { Diuretics } \\
\text { Calcium channel blockers }\end{array}$ \\
\hline CHARISMA $(52,53)$ & $\begin{array}{l}15603 \text { patients with } \\
\text { CV disease or multiple } \\
\text { CV risk factors } \\
\text { Mean age } 64.0\end{array}$ & $\begin{array}{l}\text { Clopidogrel plus } \\
\text { aspirin vs. placebo plus } \\
\text { aspirin }\end{array}$ & $\begin{array}{l}\text { Clopidogrel }(75 \mathrm{mg}) \text { plus aspirin } \\
(75-162 \mathrm{mg}) \\
\text { Placebo plus aspirin }(75-162 \mathrm{mg})\end{array}$ & $\begin{array}{l}\text { Past or current smoking } \\
\text { Hypertension } \\
\text { Hypercholesterolemia } \\
\text { Congestive heart failure } \\
\text { Prior MI } \\
\text { Atrial fibrillation } \\
\text { Prior stroke } \\
\text { Prior transient ischemic attack } \\
\text { Diabetes } \\
\text { Peripheral arterial disease } \\
\text { Prior PCI } \\
\text { Prior CABG }\end{array}$ \\
\hline MATCH (54) & $\begin{array}{l}7599 \text { patients with } \\
\text { recent ischemic stroke } \\
\text { or transient ischemic } \\
\text { attack and at least one } \\
\text { additional CV risk } \\
\text { factor } \\
\text { Mean age } 66.3\end{array}$ & $\begin{array}{l}\text { Clopidogrel plus } \\
\text { aspirin vs. clopidogrel } \\
\text { plus placebo }\end{array}$ & $\begin{array}{l}\text { Clopidogrel }(75 \mathrm{mg}) \text { plus aspirin } \\
(75-162 \mathrm{mg}) \\
\text { Clopidogrel }(75 \mathrm{mg}) \text { plus placebo }\end{array}$ & $\begin{array}{l}\text { Previous ischemic stroke } \\
\text { Previous transient ischemic attack } \\
\text { Previous MI } \\
\text { Angina pectoris } \\
\text { Symptomatic peripheral arterial disease } \\
\text { Hypertension } \\
\text { Diabetes mellitus } \\
\text { Hypercholesterolemia } \\
\text { Past or current smoker }\end{array}$ \\
\hline
\end{tabular}




\begin{tabular}{|c|c|c|c|c|}
\hline GRAVITAS (55) & $\begin{array}{l}2214 \text { patients with high } \\
\text { on-treatment platelet } \\
\text { reactivity after PCI } \\
\text { Mean age } 63.7\end{array}$ & $\begin{array}{l}\text { Clopidogrel high-dose } \\
\text { plus aspirin vs. } \\
\text { clopidogrel standard- } \\
\text { dose plus aspirin }\end{array}$ & $\begin{array}{l}\text { High-dose clopidogrel (600 mg LD, } \\
150 \mathrm{mg} \mathrm{MD}) \text { plus aspirin }(75-162 \\
\mathrm{mg}) \\
\text { Standard-dose clopidogrel }(75 \mathrm{mg}) \\
\text { plus aspirin }(75-162 \mathrm{mg})\end{array}$ & $\begin{array}{l}\text { Diabetes mellitus } \\
\text { Hypertension } \\
\text { Hyperlipidemia } \\
\text { Previous MI } \\
\text { Previous PCI } \\
\text { Previous CABG } \\
\text { Renal insufficiency } \\
\text { Past or current smoker } \\
\text { Aspirin } \\
\beta \text {-blocking agents } \\
\text { Angiotensin-converting enzyme inhibitors } \\
\text { Calcium channel blockers } \\
\text { Statins } \\
\text { Proton pump inhibitors }\end{array}$ \\
\hline CURRENT OASIS $7(56,57)$ & $\begin{array}{l}25086 \text { patients with } \\
\text { ACS }\end{array}$ & $\begin{array}{l}\text { Clopidogrel high-dose } \\
\text { vs. clopidogrel } \\
\text { standard-dose, plus } \\
\text { aspirin high-dose or } \\
\text { standard-dose }\end{array}$ & $\begin{array}{l}\text { High-dose clopidogrel ( } 600 \mathrm{mg} \text { LD, } \\
150 \mathrm{mg} \mathrm{MD} \text { ) or standard-dose } \\
\text { clopidogrel ( } 300 \mathrm{mg} \mathrm{LD}, 75 \mathrm{mg} \\
\text { MD) } \\
\text { High-dose aspirin ( } 300-325 \mathrm{mg}) \text { or } \\
\text { standard-dose aspirin }(75-100 \mathrm{mg})\end{array}$ & $\begin{array}{l}\text { Current tobacco use } \\
\text { Hypertension } \\
\text { Dyslipidemia } \\
\text { Diabetes mellitus } \\
\text { Previous MI } \\
\text { Previous PCI } \\
\text { Previous CABG }\end{array}$ \\
\hline Müller et al. (58) & $\begin{array}{l}700 \text { patients with } \\
\text { successful coronary } \\
\text { stenting } \\
\text { Mean age } 64.5\end{array}$ & $\begin{array}{l}\text { Clopidogrel plus } \\
\text { aspirin vs. ticlopidine } \\
\text { plus aspirin }\end{array}$ & $\begin{array}{l}\text { Clopidogrel }(75 \mathrm{mg}) \text { plus aspirin } \\
(100 \mathrm{mg}) \\
\text { Ticlopidine }(500 \mathrm{mg}) \text { plus aspirin } \\
(100 \mathrm{mg})\end{array}$ & $\begin{array}{l}\text { Diabetes mellitus } \\
\text { Previous CABG } \\
\text { Previous MI } \\
\text { Acute MI } \\
\text { Unstable angina } \\
\text { Three vessel disease } \\
\text { Glycoprotein IIb/IIIa receptor antagonist }\end{array}$ \\
\hline CLASSICS (59) & $\begin{array}{l}1020 \text { patients with } \\
\text { successful coronary } \\
\text { stenting } \\
\text { Mean age } 60\end{array}$ & $\begin{array}{l}\text { Clopidogrel plus } \\
\text { aspirin vs. ticlopidine } \\
\text { plus aspirin }\end{array}$ & $\begin{array}{l}\text { Clopidogrel (300 mg LD, } 75 \mathrm{mg} \\
\text { MD) plus aspirin ( } 325 \mathrm{mg} / \text { day) } \\
\text { Ticlopidine ( } 250 \mathrm{mg} \text { twice/day) plus } \\
\text { aspirin ( } 325 \mathrm{mg} / \text { day) }\end{array}$ & $\begin{array}{l}\text { Previous MI } \\
\text { Treatment for diabetes } \\
\text { Hypertension } \\
\text { Treatment for hypercholesterolemia } \\
\text { Past or current smoker }\end{array}$ \\
\hline TOPPS (60) & $\begin{array}{l}1016 \text { patients with } \\
\text { successful coronary } \\
\text { stenting }\end{array}$ & $\begin{array}{l}\text { Clopidogrel plus } \\
\text { aspirin vs. ticlopidine } \\
\text { plus aspirin }\end{array}$ & $\begin{array}{l}\text { Clopidogrel ( } 300 \mathrm{mg} \mathrm{LD}, 75 \mathrm{mg} \\
\text { MD) plus aspirin } \\
\text { Ticlopidine ( } 500 \mathrm{mg} \mathrm{LD}, 250 \mathrm{mg} \\
\text { twice/day MD) plus aspirin }\end{array}$ & Not specified \\
\hline
\end{tabular}




\begin{tabular}{|c|c|c|c|c|}
\hline JUMBO-TIMI 26 (61) & $\begin{array}{l}904 \text { patients } \\
\text { undergoing elective or } \\
\text { urgent PCI } \\
\text { Mean age } 60\end{array}$ & $\begin{array}{l}\text { Clopidogrel plus } \\
\text { aspirin vs. prasugrel } \\
\text { plus aspirin }\end{array}$ & $\begin{array}{l}\text { Low dose prasugrel ( } 40 \mathrm{mg} \mathrm{LD}, 7.5 \\
\mathrm{mg} \text { MD) plus aspirin ( } 325 \mathrm{mg}) \\
\text { Intermediate dose prasugrel ( } 60 \mathrm{mg} \\
\mathrm{LD}, 10 \mathrm{mg} \text { MD) plus aspirin ( } 325 \\
\mathrm{mg}) \\
\text { High dose prasugrel ( } 60 \mathrm{mg} \mathrm{LD}, 15 \\
\text { mg MD) plus aspirin }(325 \mathrm{mg}) \\
\text { Clopidogrel ( } 300 \mathrm{mg} \mathrm{LD}, 75 \mathrm{mg} \\
\text { MD) plus aspirin ( } 325 \mathrm{mg})\end{array}$ & $\begin{array}{l}\text { Smoking } \\
\text { Diabetes mellitus } \\
\text { Prior aspirin }\end{array}$ \\
\hline SWAP (62) & $\begin{array}{l}100 \text { patients with ACS } \\
\text { Mean age } 57.1\end{array}$ & $\begin{array}{l}\text { Clopidogrel plus } \\
\text { aspirin vs. prasugrel } \\
\text { plus aspirin }\end{array}$ & $\begin{array}{l}\text { Clopidogrel }(75 \mathrm{mg} \text { MD) plus } \\
\text { aspirin }(81-325 \mathrm{mg}) \\
\text { Prasugrel }(10 \mathrm{mg} \mathrm{MD}) \text { plus aspirin } \\
(81-325 \mathrm{mg})\end{array}$ & Not specified \\
\hline TRITON-TIMI 38 (63-69) & $\begin{array}{l}13608 \text { patients with } \\
\text { moderate-to-high risk } \\
\text { of ACS with scheduled } \\
\text { PCI } \\
\text { Mean age } 61\end{array}$ & $\begin{array}{l}\text { Clopidogrel plus } \\
\text { aspirin vs. prasugrel } \\
\text { plus aspirin }\end{array}$ & $\begin{array}{l}\text { Prasugrel (60 mg LD, } 10 \mathrm{mg} \text { MD) } \\
\text { plus aspirin }(75-162 \mathrm{mg}) \\
\text { Clopidogrel ( } 300 \mathrm{mg} \mathrm{LD}, 75 \mathrm{mg} \\
\text { MD) plus aspirin }(75-162 \mathrm{mg})\end{array}$ & $\begin{array}{l}\text { Hypertension } \\
\text { Hypercholesterolemia } \\
\text { Diabetes mellitus } \\
\text { Tobacco use } \\
\text { Previous MI } \\
\text { Previous CABG } \\
\text { Heparin } \\
\text { Bivalirudin }\end{array}$ \\
\hline DISPERSE-2 $(70,71)$ & $\begin{array}{l}990 \text { patients with non- } \\
\text { ST segment elevation } \\
\text { ACS } \\
\text { Mean age } 63\end{array}$ & $\begin{array}{l}\text { Clopidogrel plus } \\
\text { aspirin vs. ticagrelor } \\
\text { plus aspirin }\end{array}$ & $\begin{array}{l}\text { Ticagrelor (180 mg) plus aspirin (75- } \\
100 \mathrm{mg}) \\
\text { Ticagrelor }(90 \mathrm{mg} \text { twice/day) plus } \\
\text { aspirin }(75-100 \mathrm{mg}) \\
\text { Clopidogrel }(300 \mathrm{mg} \mathrm{LD}, 75 \mathrm{mg} \\
\text { MD) plus aspirin }(75-100 \mathrm{mg})\end{array}$ & $\begin{array}{l}\text { Diabetes mellitus } \\
\text { Prior MI } \\
\text { Prior PCI } \\
\text { Prior CABG }\end{array}$ \\
\hline ONSET/OFFSET $(72,73)$ & $\begin{array}{l}123 \text { patients with stable } \\
\text { aspirin-treated } \\
\text { coronary artery disease } \\
\text { Mean age } 64\end{array}$ & $\begin{array}{l}\text { Clopidogrel plus } \\
\text { aspirin vs. ticagrelor } \\
\text { plus aspirin vs. placebo } \\
\text { plus aspirin }\end{array}$ & $\begin{array}{l}\text { Ticagrelor (180 mg LD } 90 \mathrm{mg} \\
\text { twice/day MD) plus aspirin }(75-100 \\
\text { mg) } \\
\text { Clopidogrel ( } 600 \mathrm{mg} \mathrm{LD}, 75 \mathrm{mg} \\
\text { MD) plus aspirin }(75-100 \mathrm{mg}) \\
\text { Placebo plus aspirin }(75-100 \mathrm{mg})\end{array}$ & $\begin{array}{l}\text { Hypertension } \\
\text { Hyperlipidemia } \\
\text { Diabetes mellitus } \\
\text { Prior MI } \\
\text { Prior CABG } \\
\text { Prior PCI } \\
\text { Statins } \\
\text { Angiotensin-converting enzyme inhibitors } \\
\beta \text {-blockers } \\
\text { Diuretics } \\
\text { Organic nitrates } \\
\text { Proton pump inhibitors } \\
\text { Calcium channel blockers }\end{array}$ \\
\hline
\end{tabular}




\begin{tabular}{|c|c|c|c|c|}
\hline RESPOND (74) & $\begin{array}{l}98 \text { patients with stable } \\
\text { aspirin-treated } \\
\text { coronary artery disease } \\
\text { Mean age } 65\end{array}$ & $\begin{array}{l}\text { Clopidogrel plus } \\
\text { aspirin vs. ticagrelor } \\
\text { plus aspirin vs. placebo } \\
\text { plus aspirin }\end{array}$ & $\begin{array}{l}\text { Ticagrelor (180 mg LD, } 90 \mathrm{mg} \\
\text { twice/day MD) plus aspirin (75-100 } \\
\mathrm{mg}) \\
\text { Clopidogrel (600 mg LD, } 75 \mathrm{mg} \\
\text { MD) plus aspirin }(75-100 \mathrm{mg})\end{array}$ & Same as ONSET/OFFSET \\
\hline PLATO (75-84) & $\begin{array}{l}18624 \text { patients with } \\
\text { ACS, with or without } \\
\text { ST-segment elevation } \\
\text { Mean age } 62\end{array}$ & $\begin{array}{l}\text { Clopidogrel plus } \\
\text { aspirin vs. ticagrelor } \\
\text { plus aspirin }\end{array}$ & $\begin{array}{l}\text { Ticagrelor (180 mg LD, } 90 \mathrm{mg} \\
\text { twice/day MD) plus aspirin }(75-100 \\
\mathrm{mg}) \\
\text { Clopidogrel }(300-600 \mathrm{mg} \mathrm{LD}, 75 \mathrm{mg} \\
\text { MD) plus aspirin }(75-100 \mathrm{mg})\end{array}$ & $\begin{array}{l}\text { Habitual smoker } \\
\text { Hypertension } \\
\text { Dyslipidemia } \\
\text { Diabetes mellitus }\end{array}$ \\
\hline
\end{tabular}

Abbreviations: ACS - acute coronary syndrome; CABG - coronary-artery bypass grafting; CV - cardiovascular; LD - loading dose; MD - maintenance dose; MI - myocardial infarction; PCI - percutaneous coronary intervention; STEMI - ST segment elevation myocardial infarction

\begin{tabular}{|c|c|c|}
\hline Clinical Trial (Ref. \#) & Population Demographics & Efficacy of Treatments \\
\hline CAPRIE (42) & $\begin{array}{l}19185 \text { patients with atherosclerotic } \mathrm{CV} \\
\text { disease }\end{array}$ & $\begin{array}{l}\text { Clopidogrel decreased rates of ischemic stroke, MI or CV death }(5.32 \%) \text { more than aspirin } \\
(5.83 \%)(p=0.043)\end{array}$ \\
\hline CURE $(43,44)$ & 12562 patients & $\begin{array}{l}\text { Clopidogrel decreased combined rate of CV death, non-fatal MI or stroke }(9.3 \%) \text { more than } \\
\text { placebo }(11.4 \%)(\mathrm{RR} 0.80,95 \% \text { CI } 0.72-0.90, \mathrm{p}<0.001) \\
\text { Clopidogrel decreased rates of CV death }(5.1 \% \text { vs. } 5.5 \%) \text {, non-fatal MI }(5.2 \% \text { vs. } 6.6 \%) \text { or } \\
\text { stroke }(1.2 \% \text { vs. } 1.4 \%) \text { more than placebo }\end{array}$ \\
\hline PCI-CURE (45) & $\begin{array}{l}2658 \text { patients with non-ST segment } \\
\text { elevation ACS undergoing PCI }\end{array}$ & $\begin{array}{l}\text { Clopidogrel decreased rates of CV death, non-fatal MI or stroke }(4.5 \%) \text { more than placebo } \\
(6.4 \%)(\mathrm{RR} 0.70,95 \% \text { CI } 0.50-0.97, \mathrm{p}=0.03)\end{array}$ \\
\hline CREDO (46) & 2116 patients undergoing elective PCI & $\begin{array}{l}\text { Clopidogrel did not reduce combined risk of death, MI or urgent target vessel revascularization } \\
\text { more than placebo } \\
\text { Clopidogrel associated with reduced risk of ischemic adverse events }\end{array}$ \\
\hline CARESS (47) & $\begin{array}{l}107 \text { patients with asymptomatic } \\
\text { microembolic signals at baseline }\end{array}$ & $\begin{array}{l}\text { Clopidogrel decreased incidence of patients positive for microembolic signals }(43.8 \%) \text { more } \\
\text { than placebo }(72.7 \%) \text { at day } 7 \text { (risk reduction } 39.8 \%, 95 \% \text { CI } 13.8-58.0 \%, p=0.0046) \\
\text { No difference in the rate of microembolic signals per hour between regimens }\end{array}$ \\
\hline CLARITY-TIMI 28 (48) & 3491 patients with STEMI & $\begin{array}{l}\text { Clopidogrel decreased rates of infarct-related occluded artery, death or recurrent MI more than } \\
\text { placebo }(\mathrm{p}<0.001) \\
\text { Clopidogrel decreased rates of } \mathrm{CV} \text { death, recurrent } \mathrm{MI} \text { or recurrent ischemia leading to the need } \\
\text { for urgent revascularization more than placebo }(\mathrm{p}=0.03)\end{array}$ \\
\hline PCI-CLARITY (49) & 1863 patients undergoing PCI & $\begin{array}{l}\text { Clopidogrel decreased rates of CV death, MI or stroke more than placebo (OR } 0.59,95 \% \mathrm{CI} \\
0.43-0.81, \mathrm{p}=0.001)\end{array}$ \\
\hline ECG CLARITY-TIMI 28 (50) & 2431 patients with STEMI & $\begin{array}{l}\text { Clopidogrel decreased rates of CV death or MI in patients with partial }(\mathrm{p}=0.003) \text { or complete } \\
(\mathrm{p}=0.056) \mathrm{ST} \text {-segment resolution at } 90 \mathrm{~min} \text { more than placebo }\end{array}$ \\
\hline
\end{tabular}


Table 4. Continued.....

COMMIT (51)

45852 patients with acute MI

CHARISMA (52)

CHARISMA (53)

MATCH (54)

GRAVITAS (55)

CURRENT OASIS 7 (56)

CURRENT OASIS 7 (57)

Müller et al. (58)

CLASSICS (59)

TOPPS (60)

JUMBO-TIMI 26 (61)

SWAP (62)

TRITON-TIMI 38 (63)

TRITON-TIMI 38 (64)
15603 patients with CV disease or risk factors

9478 patients with documented prior MI, ischemic stroke or symptomatic PAD peripheral arterial disease

7599 patients with recent ischemic stroke or transient ischemic attack and risk factors 2214 patients with high on-treatment platelet reactivity after PCI

25086 patients with ACS

17263 patients with ACS undergoing PCI

700 patients with successful coronary stenting

1020 patients with successful coronary stenting

1016 patients with successful coronary stenting

904 patients undergoing elective or urgent PCI

100 patients with ACS

13608 patients with moderate-to-high risk of ACS with scheduled PCI

13457 patients with ACS undergoing PCI
Clopidogrel decreased combined rate of CV death, MI or stroke $(9.2 \%)$ more than placebo $(10.1 \%)(\mathrm{p}=0.002)$

Clopidogrel decreased rates of CV death $(7.5 \%$ vs. $8.1 \%)$ or MI $(1.2 \%$ vs. $1.4 \%)$ more than placebo, with the same rate of stroke $(0.6 \%)$

Clopidogrel efficient in patients with symptomatic atherothrombosis and potentially harmful in patients with $\mathrm{CV}$ risk factors

Clopidogrel decreased rate of CI death, MI or stroke $(7.3 \%)$ more than placebo $(8.8 \%)(\mathrm{HR}$ $0.83,95 \%$ CI $0.72-0.96, p=0.01$ )

Clopidogrel decreased rate of hospitalizations for ischemia (11.4\%) more than placebo $(13.2 \%)$ (HR 0.86, 95\% CI 0.76-0.96, $\mathrm{p}=0.008$ )

Non-significant difference in reducing major $\mathrm{CV}$ events between aspirin and placebo

No difference in incidence of $\mathrm{CV}$ death, non-fatal MI or stent thrombosis between clopidogrel high-dose and clopidogrel standard-dose

Superior antiplatelet effect in high-dose regimen

Clopidogrel high-dose decreased rates of stent thrombosis more than clopidogrel standard-dose

(HR 0.68, 95\% CI 0.55-0.85, $\mathrm{p}=0.001$ )

Aspirin dose had no significant effect

Clopidogrel dose had no effect on incidence of CV death, MI or stroke

Clopidogrel high-dose decreased rates of stent thrombosis more than clopidogrel standard-dose (HR 0.54, 95\% CI 0.39-0.74, p=0.0001)

Rates of primary cardiac events (CV death, urgent target vessel revascularization,

angiographically-evident thrombotic stent occlusions or non-fatal MI) comparable between ticlopidine and clopidogrel

Rates of major cardiac events comparable between ticlopidine and clopidogrel

Frequency of stent thrombosis and $\mathrm{CV}$ death comparable between ticlopidine and clopidogrel

Slightly lower incidence of 30-day major cardiac adverse events including MI, recurrent ischemia and clinical target vessel thrombosis in prasugrel patients compared to clopidogrel patients

Switching from clopidogrel maintenance dose to prasugrel associated with enhanced antiplatelet activity

Prasugrel decreased rates of $\mathrm{CV}$ death, non-fatal MI or non-fatal stroke more than clopidogrel (HR 0.81, 95\% CI 0.73-0.90, $\mathrm{p}<0.001$ )

Prasugrel decreased rates of MI $(\mathrm{p}<0.001)$, urgent target-vessel revascularization infarction

$(\mathrm{p}<0.001)$ and stent thrombosis $(\mathrm{p}<0.001)$ more than clopidogrel

Prasugrel superior to clopidogrel in preventing ischemic events Net clinical benefit superior with prasugrel compared to clopidogrel 


\section{Table 4. Continued..... \\ TRITON-TIMI 38 (65)}

TRITON-TIMI 38 (66)

TRITON-TIMI 38 (67)

TRITON-TIMI 38 (68)

TRITON-TIMI 38 (69)

DISPERSE-2 $(70,71)$

ONSET/OFFSET (72)

PLATO (75)

PLATO (76)

PLATO (79)

PLATO (82)
13608 patients with ACS with initial nonfatal CV events, MI or stroke 13608 patients with ACS

12844 patients with moderate-to-high risk of ACS with coronary stent

3534 patients with PCI for STEMI

346 patients with ACS undergoing CABG 990 patients with non-ST-segment elevation $\mathrm{ACS}$

123 patients with stable aspirin-treated coronary artery disease

18624 patients with ACS

13408 patients with ACS planned for invasive strategy

7544 patients with ACS with ST-segment elevation or left bundle-branch block 5216 patients with ACS intended for noninvasive management
Prasugrel decreased rates of CV events, MI or stroke more than clopidogrel (HR $0.65,95 \% \mathrm{CI}$ $0.46-0.92, \mathrm{p}=0.016$ )

Prasugrel reduced the risk of CV events, MI or stroke more than clopidogrel in patients with (HR $0.70, p<0.001$ ) and without diabetes mellitus (HR 0.86, $\mathrm{p}=0.02$ ), and in patients with diabetes mellitus receiving (HR 0.63, $\mathrm{p}=0.009$ ) or not receiving insulin (HR 0.74, $\mathrm{p}=0.009)$

Prasugrel reduced the risk of $\mathrm{CV}$ death, non-fatal MI or non-fatal stroke more than clopidogrel in stented cohort (HR 0.81, $\mathrm{p}=0 \cdot 0001$ )

Prasugrel associated with fewer ischemic outcomes, including stent thrombosis, compared to clopidogrel

Prasugrel reduced the risk of $\mathrm{CV}$ death, non-fatal MI or non-fatal stroke more than clopidogrel (HR 0.79, 95\% CI 0.65-0.97, $\mathrm{p}=0.0221$ )

Prasugrel reduced the risk of $\mathrm{CV}$ death, non-fatal MI or urgent target vessel revascularisation more than clopidogrel at day 30 (HR $0.75,95 \%$ CI $0.59-0.96, p=0.0205$ ) and at month 15 (HR $0.79,95 \%$ CI $0.65-0.97, p=0.0250$ )

Prasugrel reduced mortality more than clopidogrel $(\mathrm{p}=0.025)$

Ticagrelor superior platelet inhibitor to clopidogrel

Ticagrelor associated with faster and more efficient rate of platelet inhibition compared to clopidogrel $(\mathrm{p}<0.0001)$

Ticagrelor decreased combined rates of $\mathrm{CV}$ death, $\mathrm{MI}$ and stroke more than clopidogrel (HR $0.84,95 \%$ CI $0.77-0.92, \mathrm{p}<0.001)$

Ticagrelor decreased MI alone $(5.8 \%$ vs $6.9 \%, \mathrm{p}=0.005)$ and $\mathrm{CV}$ death alone $(4.0 \%$ vs. $5.1 \%$, $\mathrm{p}=0.001$ ) more than clopidogrel

Ticagrelor decreased combined rates of $\mathrm{CV}$ death, MI and stroke more than clopidogrel (HR $0.84,95 \%$ CI $0.75-0.94, \mathrm{p}=0 \cdot 0025)$

Ticagrelor decreased MI (HR 0.80, 95\% CI 0.69-0.92, $\mathrm{p}=0.0023$ ) and CV death (HR 0.82, 95\% CI $0.68-0.98, \mathrm{p}=0.0250$ ) more than clopidogre

Ticagrelor decreased combined rates of CV death, MI and stroke (10.8\%) more than clopidogrel (9.4\%) (HR 0.87, 95\% CI 0.75-1.01, p<0.07)

Ticagrelor decreased combined rates of CV death, MI and stroke (12.0\%) more than clopidogrel (14.3\%) (HR 0.85, 95\% CI 0.73-1.00, $\mathrm{p}=0.04)$

Overall death rate lower in ticagrelor patients $(6.1 \%)$ compared to clopidogrel patients $(8.2 \%)$ (HR $0.75,95 \%$ CI $0.61-0.93, \mathrm{p}=0.01$ )

Abbreviations: ACS - acute coronary syndrome; CABG - coronary-artery bypass grafting; CI - confidence interval; CV - cardiovascular; HR - hazard ratio; MI - myocardial infarction; PCI - percutaneous coronary intervention; STEMI - ST segment elevation myocardial infarction; RR - risk ratio 
Table 5. Adverse drug reactions of platelet inhibitors in clinical trials

Clinical Trial (Ref. \#) $\quad$ Population Demographics

CAPRIE (42)

19185 patients with atherosclerotic $\mathrm{CV}$ disease

CURE $(43,44)$

PCI-CURE (45)

CREDO (46)

CARESS (47)

CLARITY-TIMI 28 (48)

PCI-CLARITY (49)

COMMIT (51)

CHARISMA (53)

MATCH (54)

GRAVITAS (55)

CURRENT-OASIS 7 (56)

CURRENT-OASIS 7 (57)

Müller et al. (58)

CLASSICS (59)

TOPPS (60)

JUMBO-TIMI $26(61)$
12562 patients

2658 patients with non-ST segment elevation ACS undergoing PCI

2116 patients undergoing elective PCI

107 patients with asymptomatic microembolic signals at baseline

3491 patients with STEMI

1863 patients undergoing PCI

45852 patients with acute $\mathrm{MI}$

9478 patients with documented prior MI ischemic stroke or symptomatic PAD periphera arterial disease

7599 patients with recent ischemic stroke or transient ischemic attack and risk factors

2214 patients with high on-treatment platelet reactivity after $\mathrm{PCI}$

25086 patients with ACS

1726325086 patients with ACS undergoing PC

700 patients with successful coronary stenting

1020 patients with successful coronary stenting

1016 patients with successful coronary stenting 904 patients undergoing elective or urgent PCI
Adverse Drug Reactions

Rash, diarrhea, indigestion, nausea, vomiting bleeding disorders, intracranial hemorrhage, gastrointestinal hemorrhage, abnormal liver function

Incidence of rash higher in clopidogrel compared to aspirin $(\mathrm{p}<0.05)$

ncidence of bleeding ( RR 1.69, $\mathrm{p}<0.001$ ), especially major bleeding ( $R R 1.38, p=0.001)$,

higher in clopidogrel $(3.7 \%)$ compared to placebo $(2.7 \%)$

Incidence of major bleeding comparable between clopidogrel and placebo

Risk of minor bleeding following PCI higher in clopidogrel $(3.5 \%)$ compared to placebo $(2.1 \%)$

(RR 1.68, 95\% CI 1.06-2.68, $\mathrm{p}=0.03$ )

Incidence of bleeding comparable between clopidogrel and placebo

Incidence of bleeding or recurrent vascular events comparable between clopidogrel and placebo

Incidence of major bleeding and intracranial hemorrhage comparable between clopidogrel and placebo

Incidence of major or minor bleeding comparable between clopidogrel and placebo Incidence of bleeding comparable between clopidogrel and placebo

Incidence of severe bleeding comparable between clopidogrel and placebo

Incidence of moderate bleeding higher in clopidogrel (2.0\%) compared to placebo $(1.3 \%)(\mathrm{HR}$ $1.60,95 \%$ CI $1.16-2.20, p=0.001)$

Incidence of major (HR 1.36, 95\% CI 0.86-1.86, p<0.0001), minor (HR 2.16, 95\% CI 0.64-

$1.88, \mathrm{p}<0.0001$ ) and life-threatening bleeding (HR 1.26, 95\% CI 1.51-2.81, $<<0.0001$ ) higher in clopidogrel plus aspirin compared to clopidogrel plus placebo

Incidence of bleeding comparable between clopidogrel high-dose and clopidogrel standard-dose

Incidence of major bleeding higher in clopidogrel double-dose compared to clopidogrel standard-dose (HR 1.24, 95\% CI 1.05-1.46, $\mathrm{p}=0.01$ )

Incidence of major bleeding higher in clopidogrel double-dose compared to clopidogrel standard-dose (HR 1.41, 95\% CI 1.09-1.83, p=0.009)

Incidence of non-cardiac events (non-cardiac death, hemorrhagic complications, vascular complications, stroke, leukopenia or thrombocytopenia, intolerance) higher in ticlopidine $(9.6 \%)$ compared to clopidogrel $(4.5 \%)(\mathrm{p}=0.01)$

Major peripheral or bleeding complications, skin disorders, allergy, gastrointestinal disorders Incidence of major peripheral or bleeding complications, neutropenia, thrombocytopenia or early discontinuation of study drug as the result of non-cardiac ADRs higher in ticlopidine (9.1\%) compared to clopidogrel $(4.6 \%)(\mathrm{p}=0.005)$

Incidence of side effects higher in ticlopidine (3.64\%) compared to clopidogrel $(1.62 \%)$

Incidence of hemorrhagic complications comparable between prasugrel and clopidogre 


\begin{tabular}{ll}
\hline Table 5. Continued..... & \\
\hline TRITON-TIMI $38(63)$ & $\begin{array}{l}13608 \text { patients with moderate-to-high risk ACS } \\
\text { with scheduled PCI }\end{array}$
\end{tabular}

with scheduled PCI

TRITON-TIMI 38 (64)

13457 patients with ACS undergoing PCI

TRITON-TIMI 38 (65)

TRITON-TIMI 38 (66)

TRITON-TIMI 38 (68)

DISPERSE-2 (70)

ONSET/OFFSET (72)

ONSET/OFFSET (73)

RESPOND (74)

PLATO (75) $\mathrm{CV}$ events, MI infarction or stroke

13608 patients with ACS

3534 patients with ACS presenting with STEM

990 patients with non-ST segment elevation ACS

123 patients with stable aspirin-treated coronary artery disease

123 patients with stable aspirin-treated coronary artery disease

98 patients with stable aspirin-treated coronary artery disease

18624 patients with ACS
13608 patients with ACS with initial non-fatal
Incidence of major (HR 1.32, 95\% CI 1.03-1.68, $\mathrm{p}=0.03)$, life-threatening $(\mathrm{p}=0.01)$ and fatal bleeding $(\mathrm{p}=0.002)$ higher in prasugrel compared to clopidogrel

Incidence of non-fatal bleeding comparable between prasugrel and clopidogrel

Incidence of major non-CABG bleeding similar between prasugrel and clopidogrel during the first 3 days and higher in prasugrel compared to clopidogrel after day 3

Major bleeding infrequent

Incidence of major bleeding higher in prasugrel compared to clopidogrel in patients without diabetes mellitus (HR 1.43, $\mathrm{p}=0.02$ ) and similar between regimens in patients with diabetes mellitus

Incidence of major bleeding after CABG higher in prasugrel compared to clopidogrel $(p=0.003)$

Incidence of major bleeding unrelated to $\mathrm{CABG}$, life-threatening bleeding, or major or minor bleeding comparable between prasugrel and clopidogrel

Chest pain, headache, nausea, insomnia, diarrhea, hypotension, dizziness, syncope, rash Incidence of major or minor bleeding comparable between ticagrelor and clopidogrel Incidence of asymptomatic ventricular pauses $>2.5 \mathrm{sec}$ higher in ticagrelor $90 \mathrm{mg}$ twice/day and ticagrelor $180 \mathrm{mg} /$ day compared to clopidogrel $(\mathrm{p}=0.01)$

Incidence of dyspnea higher in ticagrelor $180 \mathrm{mg} /$ day compared to clopidogrel $(\mathrm{p}<0.0002)$ Incidence of dyspnea judged by physician to be related to studied drug higher in ticagrelor $(24.1 \%)$ compared to clopidogrel $(4.0 \%)(\mathrm{p}<0.01)$

Incidence of dyspnea higher in ticagrelor $(38.6 \%)$ compared to clopidogrel $(9.3 \%)$

Incidence of dyspnea higher in ticagrelor compared to clopidogrel

Incidence of bleeding, major bleeding or life-threatening bleeding comparable between ticagrelor and clopidogrel

Incidence of procedure-unrelated bleeding higher with ticagrelor compared to clopidogrel Incidence of major bleeding not related to $\mathrm{CABG}$ higher in ticagrelor $(4.5 \%)$ compared to clopidogrel $(3.8 \%)(\mathrm{p}=0.03)$

Incidence of drug discontinuation due to ADRs higher in ticagrelor (7.4\%) compared to clopidogrel $(6.0 \%)(\mathrm{p}<0.01)$

Incidence of dyspnea higher in ticagrelor (13.8\%) compared to clopidogrel (7.8\%) (HR 1.84 $95 \%$ CI $1.68-2.02, \mathrm{p}<0.001$ )

Incidence of dyspnea requiring treatment discontinuation higher in ticagrelor $(0.9 \%)$ compared to clopidogrel (0.1\%) (HR 6.12, 95\% CI 3.41-11.01, p $<0.001)$

Incidence of ventricular pauses $\geq 3 \mathrm{sec}$ higher in ticagrelor $(5.8 \%)$ compared to clopidogre $(3.6 \%)(\mathrm{p}<0.01)$

Incidence of major bleeding or life-threatening bleeding comparable between ticagrelor and clopidogre 


\section{Table 5. Continued.....}

\section{PLATO (77)}

PLATO (79)

PLATO (80)

PLATO (81)

PLATO (82)

PLATO (83)

PLATO (84)
15202 patients with ACS

7544 patients with ACS with ST segment elevation or left bundle-branch block

18624 patients with ACS

1261 patients with ACS undergoing CABG

5216 patients with ACS intended for non-

invasive management

2908 patients with ACS undergoing prospective

continuous electrocardiographic assessment

18421 patients with ACS
Incidence of dyspnea higher in ticagrelor (14.4\%) compared to clopidogrel (8.3\%) (HR 1.84,

95\% CI 1.66-2.04, $\mathrm{p}=0.04$ )

Incidence of dyspnea higher in ticagrelor $(12.6 \%)$ compared to clopidogrel $(8.4 \%)(\mathrm{p}<0.0001)$

Incidence of major or severe bleeding comparable between ticagrelor and clopidogrel

Incidence of bleeding not related to $\mathrm{CABG}$ higher in ticagrelor (4.5\%) compared to clopidogrel $(3.8 \%)(\mathrm{p}=0.02)$

Incidence of procedure-unrelated major bleeding higher in ticagrelor $(3.1 \%)$ compared to clopidogrel $(2.3 \%)(p=0.05)$

Incidence of major or severe bleeding comparable between ticagrelor and clopidogrel

Incidence of major or non-CABG-related major bleeding higher in ticagrelor compared to clopidogrel patients (n.s.)

Incidence of ventricular pauses $\geq 3$ sec higher in ticagrelor (5.8\%) compared to clopidogrel $(3.6 \%)(\mathrm{RR} 1.61, \mathrm{p}=0.006)$ during first week of treatment

Incidence of ventricular pauses $\geq 3 \mathrm{sec}$ at 1 month (most asymptomatic) comparable between ticagrelor and clopidogrel

Incidence of dyspnea higher in ticagrelor (14.5\%) compared to clopidogrel $(8.7 \%)$

Incidence of dyspnea judged by physician to be related to studied drug higher in ticagrelor $(15.0 \%)$ compared to clopidogrel patients $(6.9 \%)(\mathrm{p}<0.0001)$

Abbreviations: ACS - acute coronary syndrome; CABG - coronary-artery bypass grafting; CV - cardiovascular; HR - hazard ratio; MI - myocardial infarction; n.s. - not significant; PCI - percutaneous coronary intervention; STEMI - ST segment elevation myocardial infarction; RR - risk ratio 